THESIS

\title{
OPTICAL MEASUREMENT TECHNIQUES FOR IN-LINE PROCESS CONTROL IN CdS/CdTe SOLAR CELL MANUFACTURING
}

\author{
Submitted by \\ Jason Michael Kephart \\ Department of Mechanical Engineering
}

In partial fulfillment of the requirements

For the Degree of Master of Science

Colorado State University

Fort Collins, Colorado

Fall 2011

Master's Committee:

Advisor: Walajabad Sampath

James Sites

Anders Olsson 
Copyright by Jason Michael Kephart 2011

All Rights Reserved 


\begin{abstract}
OPTICAL MEASUREMENT TECHNIQUES FOR IN-LINE PROCESS CONTROL IN CdS/CdTe SOLAR CELL MANUFACTURING
\end{abstract}

$\mathrm{CdS} / \mathrm{CdTe}$ solar cells have achieved gigawatt-scale commercial production at a lower cost than traditional crystalline silicon photovoltaics. With large-scale production of semiconductor devices, process control is critical to ensuring consistent quality. While there are many classes of materials characterization techniques including scanning probe, x-ray, electronic techniques, optical techniques are particularly promising for in-line structural characterization and process control. They are fast, non-contact, occupationally safe, precise, and can be performed immediately after film deposition to detect problems early in the manufacturing process.

Two such optical techniques are examined here: spectroscopic ellipsometry and scanning white light interferometry. Spectroscopic ellipsometry consists of measuring the change in polarization of light reflected from a thin film structure. Fitting a model to the data provides structural information such as layer thickness and optical properties. Visually rough films can be a major obstacle to the use of ellipsometry, and processing options are explored to reduce roughness to acceptable levels. Ellipsometry has been shown to be accurate within $4 \%$ of thickness for the CdTe absorber layer and the CdS 
window layer can be measured accurately under the CdTe absorber for layers thicker than about $100 \mathrm{~nm}$.

Scanning white light interferometry (SWLI) uses the interference of reflected light from a surface to construct an extremely precise depth profile. This technique was examined for measurement of surface morphology and roughness as well as the measurement of film step heights, which could indicate whether or not the technique can be used for scribe metrology. Though the lateral resolution is limited by the use of optical microscopy, it has been shown that surface features can be resolved. Step height measurements match stylus profilometry very closely over a wide range of device thicknesses. 


\section{ACKNOWLEDGEMENTS}

I would like to thank my advisor, Professor W.S. Sampath, for his guidance. I would also like to thank my committee members, Professor James Sites and Dr. Anders Olsson, for their time and commitment. I would like to thank the members of the NSF I/UCRC for Next Generation Photovoltaics for making this work possible.

I would like to show my appreciation for the efforts of other members of our laboratory, especially Paul Kobyakov and Kevin Walters, for their work in designing the Advanced Research Deposition System which has made my research possible. Keegan Barricklow of Abound Solar has been instrumental in the installation, debugging, and analysis of our equipment and processes, and I would like to thank him for his contributions to the laboratory.

I thank Drs. Kohli and McCurdy of the Central Instrumentation Facilities for their instruction in the use of characterization equipment such as the spectroscopic ellipsometer. Without the guidance and support of Jack Clark of Surface Analytics, LLC, SWLI studies would not have been possible, and I offer him many thanks. Thanks also go to Steve Barnes of Abound Solar for help with AFM and profilometry.

Lastly but most importantly I would like to thank my family for their support and inspiration through my life. My father has provided a great example to me as a researcher and did much to stoke my curiosity as a child. My mother has always encouraged and embraced my interest in science, and together they have given much to allow me to follow my passions. Thanks also go to the rest of my family members for their love and support. 


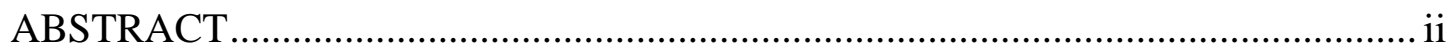

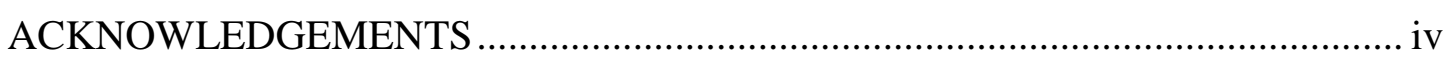

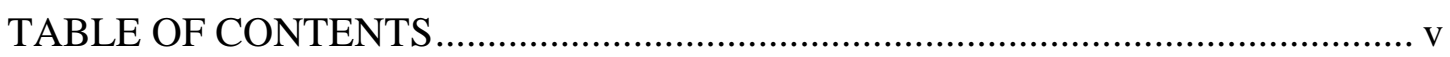

CHAPTER 1: INTRODUCTION AND MOTIVATION ................................................. 1

$1.1 \quad$ The Global Energy Picture ……………………….................................. 1

1.2 The Promise of Solar Energy ............................................................... 2

1.3 Basic Device Physics of the Solar Cell ....................................................... 4

1.4 Design of a CdS/CdTe solar cell ............................................................ 5

CHAPTER 2: OPTICAL TECHNIQUES FOR THIN-FILM CHARACTERIZATION

2.1 An Introduction to Optical Characterization Techniques................................. 8

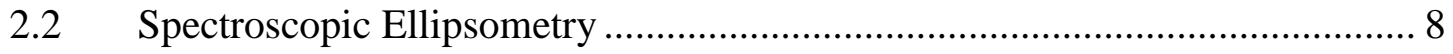

2.3 Model construction in spectroscopic ellipsometry ……….............................. 10

$2.4 \quad$ Scanning White Light Interferometry.......................................................... 12

CHAPTER 3: EXPERIMENTAL DETAILS .................................................... 14

3.1 Advanced Research Deposition System ....................................................... 14

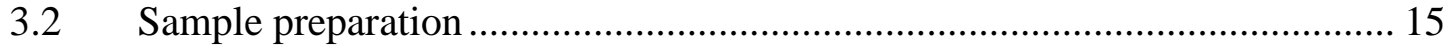

CHAPTER 4: ANALYSIS OF SPECTROSCOPIC ELLIPSOMETRY RESULTS . 19

$4.1 \quad$ Background and Introduction ............................................................... 19

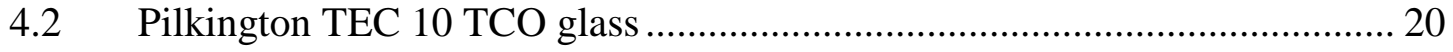

4.3 Cadmium sulfide layers deposited on TEC 10 …....................................... 22

$4.4 \mathrm{CdS} / \mathrm{CdTe}$ structures deposited on TEC 10 ……………………………..... 24

4.5 Effects of the $\mathrm{CdCl}_{2}$ post-treatment on $\mathrm{CdS} / \mathrm{CdTe}$ structures ......................... 34

4.6 Through-the-glass ellipsometry ………………......................................... 37

CHAPTER 5: ANALYSIS OF SCANNING WHITE LIGHT INTERFEROMETRY

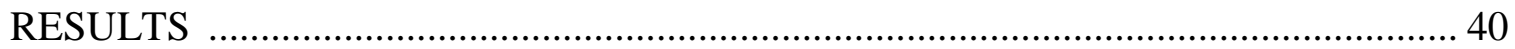

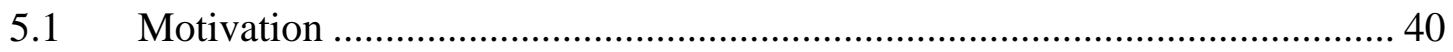

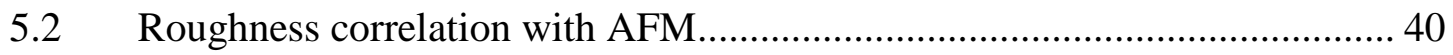

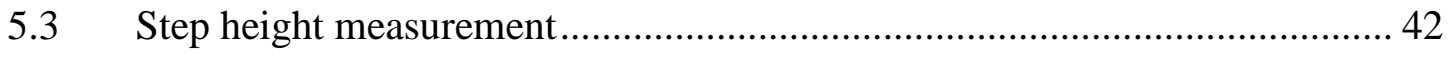

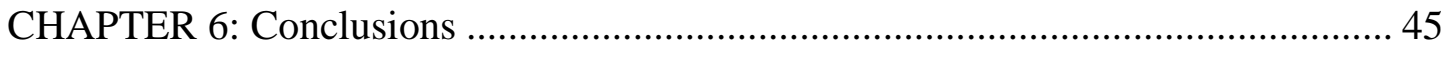


6.1 Perspective and Summary of Results .................................................. 45

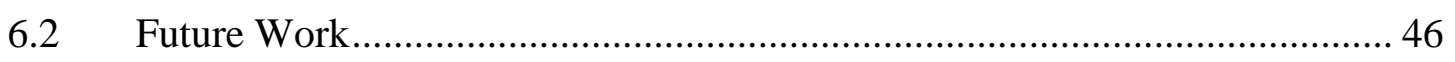

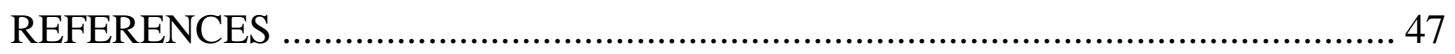




\section{CHAPTER 1: INTRODUCTION AND MOTIVATION}

\subsection{The Global Energy Picture}

Since the Industrial Revolution, man has produced energy on a large scale to increase economic output, replacing human labor with machines. Increasing energy use has enabled higher quality of life across the world as well as a vastly larger population. Since 2007, developing (non-OECD) countries use more energy than developed countries, and are forecast by the Energy Information Administration to consume 63 percent more energy by 2035 [1]. With such a close coupling between energy consumption and economic growth, being able to reliably and sustainably meet growing world demand will be critical to continued peaceful development [2].

Currently, the vast majority of the world's energy production is from fossil fuels: coal, natural gas, and petroleum. Sixty-four percent of grid electricity in the world is produced from these three fuels, with coal alone constituting 43\%. Developing countries are forecast to continue increasing their use of coal at a rate of $2 \%$ per year [3]. The abundance and low cost of coal make it an economically attractive option to meet the world's burgeoning energy demand. However, pollutants and greenhouse gases make the likely scenario of future electricity production environmentally problematic.

Because is it mainly carbon, coal has the highest greenhouse gas emissions per unit energy of all the major energy sources [3]. The overwhelming scientific consensus is that $\mathrm{CO}_{2}$ from burning fossil fuels is contributing to global warming. This is likely to cause an increase in temperature, changes in precipitation patterns, decreases in global snow cover, increases in natural disasters, and sea level rise [4]. Additional concerns related to coal 
are the other pollutants emitted by coal plants, the safety of coal mines (especially in developing countries), and the impacts of coal mining on the environment.

\subsection{The Promise of Solar Energy}

To solve the problems associated with burning fossil fuels while meeting energy demand, there are many technologies and options. The first is to increase energy efficiency by reducing the amount of energy required for manufacturing and meeting basic needs. While this is a critical aspect of any strategy for moving to a carbon neutral society, to first order the world will still need a comparable amount of energy.

The next option is to rely more heavily on natural gas or coal power with carbon capture and sequestration. Natural gas is predicted by the Energy Information Administration to account for 60 percent of new U.S. electric power capacity up to 2035 [1]. While emitting less carbon dioxide, natural gas is not a renewable or carbon neutral technology. The economics and science of carbon sequestration remain uncertain in terms of cost and the technical ability to sequester carbon for long timescales [1].

Nuclear and hydroelectric energy are both well-established carbon-neutral forms of electricity generation. Nuclear energy has always come with safety and security risks involved with the production of fissile material and the risk of release of radioactive materials into the environment. While it has received increased attention in recent years and new plants are being developed, the accident at the Fukushima Daiichi Nuclear Plant in Japan in March 2011 may put a damper on future projects or any mass nuclear power development [5]. Hydroelectric power contributes significantly to world electricity production, but at least in the United States, most ideal sites for dams are already being 
exploited. Hydroelectric power production in the U.S. has been flat for approximately thirty years, varying mainly due to annual variations in precipitation [6]. While both these technologies are proven, they are unlikely to be able to meet the entire demand for electricity.

Other renewable energy sources such as wind and biofuels have received a lot of attention. They are both renewable and carbon neutral, and wind turbines have begun to be commercialized on a large scale. However, wind resources are not large enough to meet world energy demand. Similarly, the amount of arable land it would take to produce a large portion of U.S. energy demands from biofuels is prohibitive and providing more than $30 \%$ of liquid fuel demand would affect food production [7].

Solar power is attractive because it is present to some degree everywhere in the world, quite reliably, and is a resource that is unquestionably large enough to meet all human energy needs. The amount of solar radiation that falls on the earth in 40 seconds is the same as world energy consumption in an entire year [8]. The United States in particular has very good solar resources, and the places with the highest insolation are often desert lands which cannot be used for agriculture. Just $0.4 \%$ of U.S.land area could meet all current electricity needs [9]. Two types of solar power are solar thermal and photovoltaics (PV). While solar thermal power is promising, photovoltaics have the advantage of converting sunlight directly into electricity and make better use of diffuse light. PV can be deployed on almost any scale including residential roofs and utility-scale fields. The costs of photovoltaic modules have dropped drastically with increasing production quantities and will likely continue to do so [10]. As a result, the installed capacity of PV modules has increased by more than $40 \%$ per year since the year 2000 [8]. 


\subsection{Basic Device Physics of the Solar Cell}

Fundamentally, a solar cell is made of one or more semiconductors. In solids, energy levels form bands, which are a range of possible energy levels for electrons to occupy. In a semiconductor material, there is a modest energy gap between the highest occupied energy state for electrons and the lowest unoccupied energy state. This differs from metals, which have no gap, and insulators, which have a large gap (relative to the thermal energy) [11].

The energy band just below the bandgap is called the valence band, and the band at the top of the band gap is called the conduction band. In a semiconductor, electrons can be excited by a sufficient amount of energy and move from the valence band to the conduction band. Both the excited electron and the empty state in the valence band, a positively charged quasiparticle called a hole, can contribute to conduction in the material. Intrinsic semiconductors have an equal number of holes and electrons; semiconductors can also be doped p-type or n-type. A dopant has an energy state in the band gap close to the conduction band (n-type) or valence band (p-type). Thermal energy can easily ionize most of these states and add an electron or hole, respectively. While the relative number of holes or electrons can vary greatly, the product of their concentrations, $n p$, depends only on the bandgap of the material and the temperature.

When a p-type semiconductor and an n-type semiconductor come in contact, they form a diode. To understand the behavior of the p-n junction it is necessary to consider the Fermi level, $\mu$. The Fermi level is the highest level occupied by an electron at $0 \mathrm{~K}$. For an n-type material the level is close to the conduction band and for a p-type material 
it is closer to the valence band. When they are placed together with no applied potential, the Fermi level must be flat across the structure; this is accomplished by electrons moving over to the p-type material and occupying holes in a thin region, annihilating free carriers in a process called depletion. This causes the p-type bands to move to a lower potential (higher energy for electrons) relative to the bands in the n-type material, and creates an electric field across the junction.

The result of a p-n junction is the formation of a diode, in which current can pass much more easily in one direction than in the other. When forward biased, the p-type material is at a more positive potential, and holes and electrons are pushed into the depletion layer, recombining and enabling current flow; for an ideal diode, this flow is exponential with the potential. In reverse bias, very few electrons have enough thermal energy to "jump" into the p-layer conduction band, and quickly fall back into the n-layer. Only the small amount of electrons in the p-layer and holes in the n-layer which can diffuse into the depletion layer contribute to the current [11].

The p-n junction is responsible for the photovoltaic effect in semiconductors. Light with sufficient energy is absorbed by the semiconductor, and an electron is excited into the conduction band, producing both a hole and an electron. The built-in electric field in the junction sweeps these carriers away from one another and can produce current that does work in an external circuit. This current is in the direction of reverse bias current and is possible due to the creation of free carriers in or near the depletion layer [12].

\subsection{Design of a CdS/CdTe solar cell}


There are many considerations in designing a highly efficient solar cell, some of which arise from the theory of an ideal diode, and some of which arise from practical considerations or departures from the ideal case. In choosing a material for a solar cell, an appropriate bandgap is critical. A semiconductor can only absorb photons with energy above the bandgap but can only collect an amount of energy from each photon which is limited by the built-in potential of the diode, which is related to the bandgap. The ideal balance depends on the spectrum of the incoming light. For solar radiation on earth, a bandgap of about 1 to 1.5 electron-volts (eV) is ideal [13].

Numerous other material properties are of great importance in choosing a semiconductor material. Impurities in semiconductors create "traps" which can immobilize a charge carrier and lead to its recombination. A highly absorbing material can absorb most light in a thinner layer, and a thin layer means less distance a charge carrier will need to travel without recombining. Alternatively, a material that is extremely pure and which has a high carrier lifetime can be made thicker and still have good performance.

In the case of cadmium telluride, its bandgap is almost ideal at $1.45 \mathrm{eV}$, and it is highly absorbing, collecting almost all light in a layer approximately one micron thick. However, it typically has low carrier density and low minority carrier lifetimes compared to competing absorber materials like silicon and $\mathrm{Cu}(\mathrm{In}, \mathrm{Ga}) \mathrm{Se}_{2}[14]$. This is due to the presence of intrinsic defects such as vacancies and substitutions, impurities, and the presence of grain boundaries in polycrystalline films. While CdTe has been doped n-type and p-type, the difficulty of making a stable and high-performing junction in a thin layer 
means that the best CdTe cells use p-type CdTe and n-type CdS in a heterojunction configuration.

The typical design of a CdS/CdTe solar cell consists of a glass substrate, a transparent conducting layer, the semiconductor layers, and a back contact. Cadmium sulfide is a high-bandgap semiconductor $(2.4 \mathrm{eV})$ which is intrinsically doped highly n-type. It has a poor hole lifetime, so light absorbed in this layer does not result in much current through the cell. Because most light should be absorbed near the p-n junction where the electric field is high, the CdS layer is made as thin as possible to minimize absorption and is placed in front of the CdTe layer. This "window" layer serves only to create the n-type partner of the junction. The CdTe layer needs to be made thick enough to accommodate the depletion width of the junction (for maximized voltage) and to absorb almost all incoming light above the bandgap energy [15]. Too thick, however, and recombination in the layer will be increased. Control of layer thickness is therefore of great importance in manufacturing these photovoltaic cells.

After deposition of the layers, the device efficiency is typically quite low due to high recombination in the device. A post-treatment in which the device is exposed to cadmium chloride at high temperature has been shown to greatly improve efficiency. While the exact mechanisms are not understood with certainty, the treatment can act like a flux, inducing re-crystallization in some cases and causing interdiffusion of sulfur and tellurium atoms [16]. 


\section{CHAPTER 2: OPTICAL TECHNIQUES FOR THIN-FILM CHARACTERIZATION}

\subsection{An Introduction to Optical Characterization Techniques}

For the determination of semiconductor properties and structures, several classes of techniques can be delineated. Techniques such as current-voltage (J-V) and capacitancevoltage $(\mathrm{C}-\mathrm{V})$ measure the behavior of electrons in the device. Electron microscopy can make very fine images of the layers and grain structure can be observed. X-ray techniques like energy dispersive spectroscopy (EDS) and x-ray photoelectron spectroscopy (XPS) provide good analysis of elemental constituents of a material [17]. Finally, optical techniques can characterize how light is reflected, transmitted, absorbed, or emitted from a material.

While an array of techniques are typically necessary for full analysis and characterization of a device structure, optical techniques are attractive for a number of reasons, especially for use as an in-line processing tool in the factory. The tools can be made to operate very quickly, they do not require vacuum, are occupationally safe, are non-destructive and non-contact, and can be relatively inexpensive as light is rather easy to produce and measure. Foremost, though, is that they do not require the production of a complete photovoltaic device to be useful. Since a large portion of the cost of a module is added after the semiconductor layers are deposited, determining the quality of these layers before extra money is spent to complete the module can save money and expose problems with the manufacturing process quickly.

\subsection{Spectroscopic Ellipsometry}


Ellipsometry involves measuring the change in polarization of light reflected off a thin-film structure. When light reflects off a surface, there are two coefficients of reflection: $r_{p}$ (parallel to the plane of the incident and reflected light beams) and $r_{s}$ (senkrecht or perpendicular). These in general are not equal and depend on the refractive index of the two materials at the interface, as well as the angle of incidence. A circularly polarized beam of light reflected from a sample will become an ellipse, thus the term ellipsometry. Two parameters, $\psi$ and $\Delta$, fully indicate the change in polarization of the light, where $\psi$ indicates the relative magnitudes of $\mathrm{r}_{\mathrm{s}}$ and $\mathrm{r}_{\mathrm{p}}$, and $\Delta$ indicates their phase difference. Equation 1 defines these two parameters mathematically.

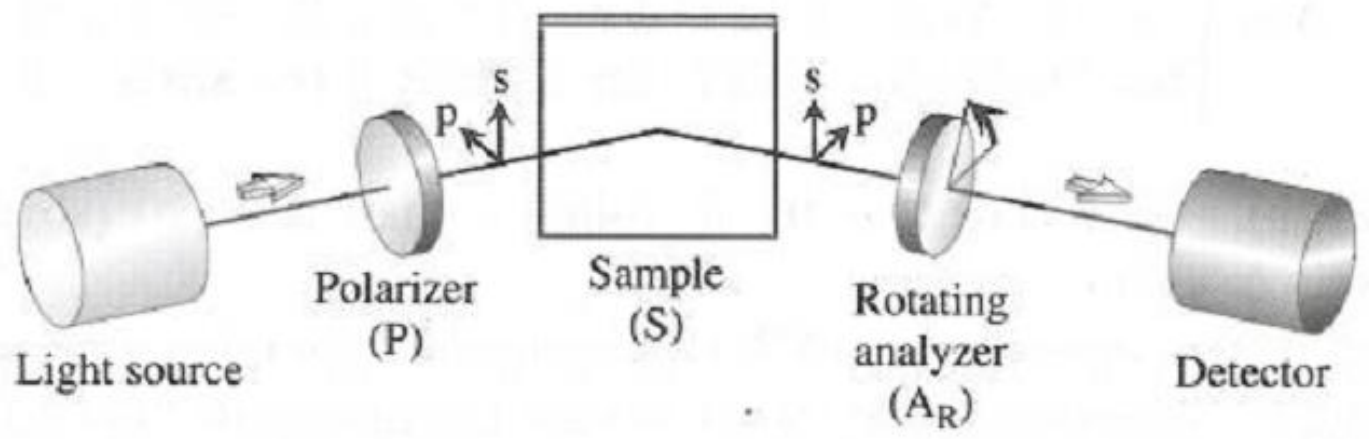

Figure 1. Schematic of a rotating analyzer ellipsometer [18].

$$
\rho \equiv \frac{r_{p}}{r_{s}}=\tan \psi e^{i \Delta}
$$

Equation 1. The polarization state of light can be defined with the parameters $\psi$ and $\Delta$ [18].

Most basically, an ellipsometer consists of a goniometer to hold the sample at the proper orientation, a light source, a polarizer, and an analyzer to measure the polarization of the reflected light. The analyzer is rotated, and the polarization of the corresponding reflected light beam is measured. These measurements can be performed at multiple wavelengths and at multiple angles of incidence, which is known as variable angle 
spectroscopic ellipsometry (VASE). Also, multiple wavelengths of light can be reflected at once, with the output spectrally resolved. This enables very fast sample times and is known as real-time spectroscopic ellipsometry [19].

When the incident light hits the sample, some of it is reflected and some is transmitted. Then, some of the light can be absorbed at the next interface or transmitted, and so on. This creates an endless combination of paths the light can take through the film stack. All of these paths that end up making it to the analyzer, which have different phases depending on their path lengths, must be combined in order to predict what the empirical data will be.

Typically, films are measured at angles of incidence near their pseudo-Brewster angles. This is where $\psi$ is most sensitive to changes in optical properties. For semiconductors this angle is usually about 70 degrees from normal [18]. Lower angles can reduce scattering from rough surfaces but reduce the sensitivity of $\psi$.

\subsection{Model construction in spectroscopic ellipsometry}

Due to the complexity of light interactions in a thin film structure, a model is created in a computer program with parameters such as refractive indices and film thicknesses, and certain parameters are allowed to vary in order to fit empirical data. For this study the WVASE32 program from J.A. Woollam was used. The Levenberg-Marquardt algorithm can be used to vary parameters and find a minimum of mean-squared error (MSE) between the empirical and model values. There is no exact MSE which is acceptable when fitting a model, and a perfect fit can always be made by allowing the optical constants to vary freely at all wavelengths. A model should be physically accurate, good 
enough to make a close fit, and with few enough parameters that they are significant and not highly correlated with one another [20]. Erroneous results with good fits can easily be obtained by allowing too many parameters to vary freely.

Often, refractive indices are allowed to vary following an absorption model with a few parameters, such as a Lorentz model, which models the response of a harmonic oscillator. This has the advantage of modeling absorption-wavelength relationships in real-world materials, such as parabolic bands or free carriers, with relatively few parameters. Since the complex refractive index is an analytic function, the refractive index can be determined from the extinction coefficient by the Kramers-Kronig relation. Therefore, using an oscillator model also guarantees that the values used obey this fundamental relationship [20].

In some cases, one wishes to model a layer consisting of multiple phases with different refractive indices, such as at a rough surface or interface. An effective medium approximation (EMA) model aims to approximate a layer consisting of multiple phases with one single set of effective optical constants $\varepsilon(\lambda)$. The Clausius-Mossotti relation models the polarization effect of a sphere in a medium. When, according to this relation, a sphere of phases $a$ and $b$ with volume fraction of phase $a f_{a}$ is placed in a host medium with dielectric constant $\varepsilon_{\mathrm{h}}$, Equation 2 must hold, where $\varepsilon$ is the effective dielectric constant. When $\varepsilon_{\mathrm{h}}$ is set to be equal to $\varepsilon$, the result is the Bruggeman EMA, shown in Equation 3, which is the only EMA used in this work [18].

Equation 2. The relation of host, effective, and phase dielectic constants in effective medium theory [18].

$$
\frac{\varepsilon-\varepsilon_{h}}{\varepsilon+2 \varepsilon_{h}}=f_{a} \frac{\varepsilon_{a}-\varepsilon_{h}}{\varepsilon_{a}+2 \varepsilon_{h}}+\left(1-f_{a)} \frac{\varepsilon_{b}-\varepsilon_{h}}{\varepsilon_{b}+2 \varepsilon_{h}}\right.
$$


Equation 3. The Bruggeman EMA $\varepsilon$ for phases $a$ and $b$ [18].

$$
f_{a} \frac{\varepsilon_{a}-\varepsilon}{\varepsilon_{a}+2 \varepsilon}+\left(1-f_{a}\right) \frac{\varepsilon_{b}-\varepsilon}{\varepsilon_{b}+2 \varepsilon}=0
$$

\subsection{Scanning White Light Interferometry}

Scanning white light interferometry is a highly precise, non-contact way to measure the surface profile of an object. A camera connected to a microscope records the intensity of light at each point on the surface. An interferometer inside the objective of the microscope causes a pattern of fringes to appear in the image. Because the light is of many different wavelengths, the coherence length of the light is low, and interference is a maximum when the sample and interferometer mirror are equidistant [21]. The amplitude of the interference fringes is monitored for this maximum condition and fit with a complex algorithm to determine the depth at each point. The lateral resolution is fundamentally diffraction limited but a pixel size of $50 \mathrm{~nm}$ is possible; depth precision can be better than one nanometer [21]. In this study, a Zygo NewView 7300 system is used along with Zygo MetroPro software for data analysis. 


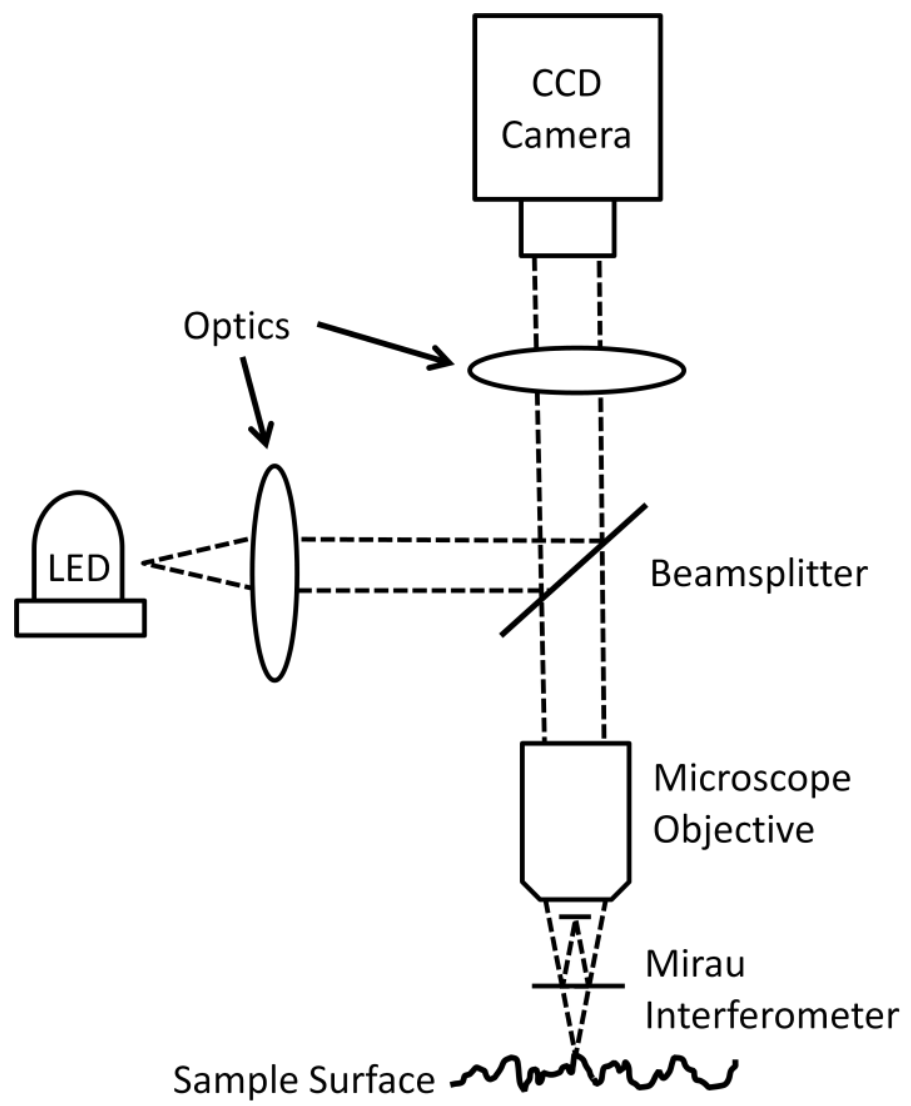

Figure 2. Layout of a Scanning White Light Interferometer (SWLI). 


\section{CHAPTER 3: EXPERIMENTAL DETAILS}

\subsection{Advanced Research Deposition System}

Semiconductor films were deposited using the Advanced Research Deposition System (ARDS) at the CSU Materials Engineering Lab. This system, depicted in Figure 3 , consists of a vacuum chamber containing nine process stations in which sublimation or heat treatments can occur. The system is designed for maximum process flexibility, and samples may go through any sequence of processes; typical processes are heating, CdS deposition, $\mathrm{CdTe}$ deposition, $\mathrm{CdCl}_{2}$ treatment, and $\mathrm{Cu}$ doping. Glass coated with a transparent conducting oxide (TCO) is transported in and out of process stations by an automated magnetic transfer arm. A program written in the LabView environment operates the magnetic transfer arm process sequence.

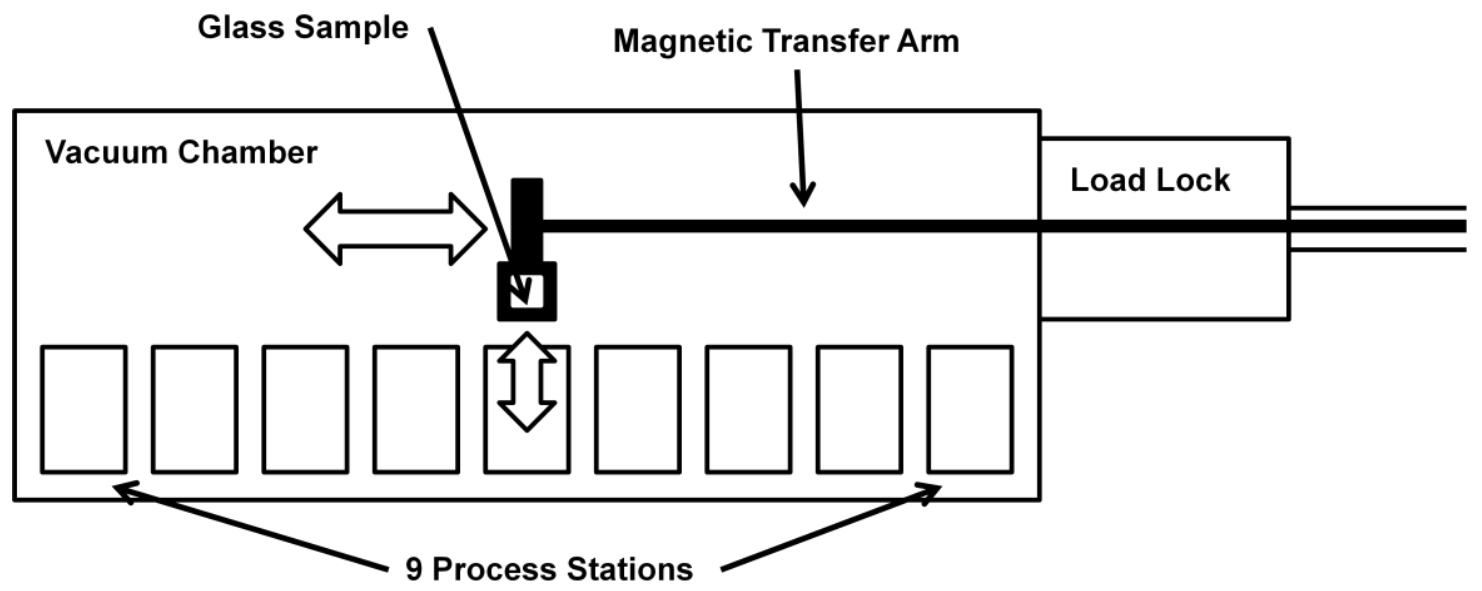

Figure 3. The Advanced Research Deposition System.

The graphite process stations have heaters that allow independent temperature control of the top and the bottom of each station. The heating elements are Ni-Cr heating wire coils embedded into the graphite sources with a cast alumina ceramic. For deposition, the station bottom holds the material to be sublimed, and the temperature of the bottom controls the sublimation rate. The TCO layer faces the bottom of the process stations. The 
top of the station primarily influences substrate temperature, which can have a large impact on grain structure.

The vacuum chamber uses a Varian VHS-6 diffusion pump containing Dow Corning 702 fluid backed by a Leybold Trivac D60 rotary vane pump. A backfill gas of $2 \% \mathrm{O}_{2}$ in $\mathrm{N}_{2}$ is held at a constant pressure of $4 \cdot 10^{-2}$ Torr by a MKS $1179 \mathrm{~A}$ mass flow controller in a digital control loop with a MKS 925 MicroPirani pressure transducer. Gas compositions are monitored with a SRS RGA 9000 and water vapor is brought to less than $2 \%$ before deposition.-

\subsection{Sample preparation}

For all samples, Pilkington TEC10 glass was used as a substrate. This glass was originally designed as a low-emissivity window glass. It consists of a 3.2-mm sheet of soda lime glass, $\mathrm{SnO}_{2}$ and $\mathrm{SiO}_{2}$ layers approximately $20 \mathrm{~nm}$ thick, and a layer of fluorinedoped tin oxide $\left(\mathrm{SnO}_{\mathrm{x}}: \mathrm{F}\right)$ which is about $400 \mathrm{~nm}$ thick and is the transparent conducting layer. The 20-nm layers reduce the color effects from the conducting thin film, but can also act as a diffusion barrier between ions in the glass and the other layers.

The glass enters the ARDS and is rapidly heated to approximately 450 degrees Celsius. It then enters the CdS deposition station, and a layer typically about 100-200 nm thick is deposited on the fluorine-doped tin oxide. A CdTe layer on the order of $2 \mu \mathrm{m}$ is deposited on the CdS. Then the film can be passivated by being exposed to a $\mathrm{CdCl}_{2}$ flux at temperature. To make an ohmic contact to the poorly conducting $\mathrm{CdTe}$, it is doped with $\mathrm{Cu}$ by several stations which either serve to control the substrate temperature or expose the film to a $\mathrm{CuCl}$ vapor. The standard time used in each station is 110 seconds. 
After cooling, the sample can be removed from the system. The $\mathrm{CdCl}_{2}$ deposition is removed with deionized water and isopropyl alcohol. The sample is numbered based on the "run," or heating cycle of the chamber, followed by the number of substrate in the sequence of that run. If the sample is to be made into a photovoltaic device, it is coated with a conductive paint. Samples produced for optical analysis are simply thin films on TCO glass and do not have conductive paint. Also, because the copper doping process introduces tiny amounts of copper and has little effect on the optical properties of the layers, it was omitted for most samples except to verify that copper does not affect optical data strongly.

In the development of the ARDS it was discovered that the films producing the best photovoltaic devices were also very rough, on the order of $500 \mathrm{~nm}$. In manufacturing, this roughness can interfere with deposition of the back electrode. It also causes a great amount of light scattering which renders ellipsometry impossible. In the attempt to make smoother films, three approaches proved successful. The first approach was to deposit rough films and polish them with a slurry of 50-nm alumina powder in ethylene glycol. This solution has been shown to produce a highly polished CdTe surface with minimal damage deep into the surface [22]. Films were mechanically rubbed with a lens wipe submerged in this solution. The resulting films were highly visually smooth.

The second approach is to lower the substrate temperature, which produces films with much smaller, columnar grains and a smooth surface. However, these conditions produce electronically poor films which are not used for making devices, and this approach is not ideal. The grains are not well coalesced and the films appear much darker to the naked eye. Third, it was determined that exposing the $\mathrm{CdS}$ to $\mathrm{CdCl}_{2}$ treatment before $\mathrm{CdTe}$ 
deposition, but with the same station temperatures, produces smooth films that have good electronic properties. These three process conditions are henceforth referred to as "hot," "cold," and "pre-treated." Temperatures vary slightly to change film thicknesses. Table 1 shows a comparison of typical station temperatures for these three conditions. Figure 4 shows a scanning electron micrograph of the surface textures of various films.

Table 1. Typical process temperatures for deposition and post-treatment

\begin{tabular}{|c|c|c|c|c|c|c|c|}
\hline \multicolumn{2}{|c|}{} & Heater & CdS & CdCl2 & CdTe & CdCl2 & Heater \\
\hline \multirow{3}{*}{ Hot } & Top & 620 & 480 & N/A & 360 & N/A & N/A \\
\cline { 2 - 8 } & Bottom & 620 & 633 & N/A & 560 & N/A & N/A \\
\hline \multirow{3}{*}{ Cold } & Top & 500 & 367 & N/A & 346 & N/A & N/A \\
\cline { 2 - 8 } & Bottom & 500 & 613 & N/A & 555 & N/A & N/A \\
\hline \multirow{3}{*}{ Pre-treated } & Top & 620 & 480 & 410 & 370 & 410 & 140 \\
\cline { 2 - 8 } & Bottom & 620 & 630 & 435 & 565 & 435 & 146 \\
\hline
\end{tabular}




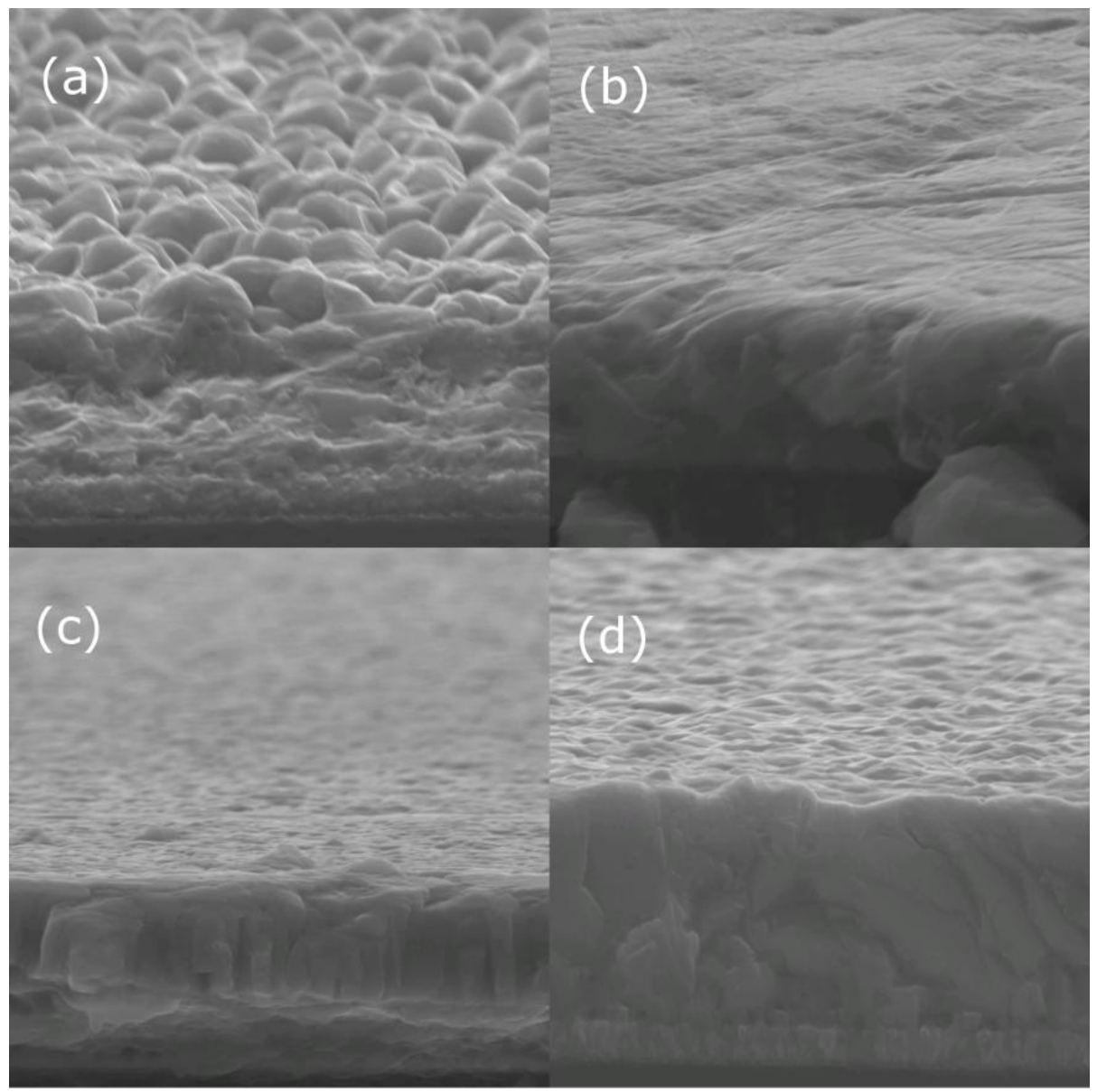

Figure 4. a) Hot process conditions b) a film from the same sample as (a) after polishing, c) a cold process condition, and d) a pre-treated process condition. 


\section{CHAPTER 4: ANALYSIS OF SPECTROSCOPIC ELLIPSOMETRY RESULTS}

\subsection{Background and Introduction}

The earliest work using spectroscopic ellipsometry on CdTe was published by Aspnes in 1984. In two papers, Aspnes describes the optical effects of a mild bromine-methanol etch on the surface of a variety of $\mathrm{Hg}_{1-\mathrm{x}} \mathrm{Cd}_{\mathrm{x}} \mathrm{Te}$ alloys, including CdTe; in these treatments an amorphous Te layer of a few angstroms can be seen at the surface [23]. The nature of anodically grown surface oxides were examined in a second paper [24].

Much work on spectroscopic ellipsometry for CdTe thin-film solar cells has been done at the University of Toledo on films deposited by RF magnetron sputtering. In results published in 1999, Wei et al. were able to measure the change in optical properties of films of $\mathrm{CdTe}_{1-\mathrm{x}} \mathrm{S}_{\mathrm{x}}$ for varying compositions of $x$. They observed a reduction, then increase in bandgap with increasing sulfur content and a shift in three critical points [25].

A similar experiment was later repeated for sputtered ternary films [26]. This research used a real-time spectroscopic ellipsometer which was incorporated into the RF sputtering system. This allowed the researchers to deposit films, cool them, and measure them without removing them from vacuum. This could be done numerous times during film deposition to observe the progress of film growth. It could also measure the film as it was being deposited. The system measures from .75 to $6.5 \mathrm{eV}$ in 2 seconds. The films are grown on crystalline silicon wafers, and the evolution of surface roughness up to $5 \mathrm{~nm}$ at the endpoint is observed [19].

Ex-situ work has also been done by the group to characterize full solar cell structures. Ellipsometry was successfully used in this case to measure layer thicknesses, critical point broadening, and grain size (indirectly from quantum effects) [27]. These effects are 
observable to the very small grain size, potentially high stress, and roughness of sputtered CdTe films. Now, work by the Toledo group is being done to measure full devices through the glass, and to measure large areas quickly [28,29]. This promises to offer realtime structural characterization of production scale modules in the manufacturing line.

\subsection{Pilkington TEC 10 TCO glass}

The first step in constructing an accurate optical model of photovoltaic devices is to model the substrate: $3.2-\mathrm{mm}$ TEC 10 TCO glass. TEC 15, which has the same structure except for a thinner $\mathrm{SnO}_{\mathrm{x}}: \mathrm{F}$ layer, was modeled successfully by Von Rottkay and Rubin [30] and similarly by others [31]. This work modeled the $\mathrm{SnO}_{2}$ layer as having a Lorentz absorption at high photon energy to model the bandgap of $\mathrm{SnO}_{2}$ at approximately $4 \mathrm{eV}$. For the $\mathrm{SnO}_{\mathrm{x}}$ :F layer, a Drude model was added to model absorption from free carriers.

The published optical model was used as a starting point for modeling the TEC 10 layers, except with a thicker conducting layer of $400 \mathrm{~nm}$ and a roughness (modeled by a Bruggeman EMA) of $30 \mathrm{~nm}$. The $\mathrm{SiO}_{2}$ layer optical properties were taken from reference values, and the glass was modeled using a Cauchy model at a fixed thickness of $3.2 \mathrm{~mm}$. Ellipsometry data was taken from $300 \mathrm{~nm}$ to $1700 \mathrm{~nm}$ wavelengths at three angles from normal $-54,57$, and 60 degrees. The sample was also measured from the glass side at an angle of 60 degrees. The parameters were iteratively changed until a good fit was obtained from both sides. The chosen parameters are given in Table 2 and the resulting model fits are given in Figure 5. 
(a)

TEC 10, film side

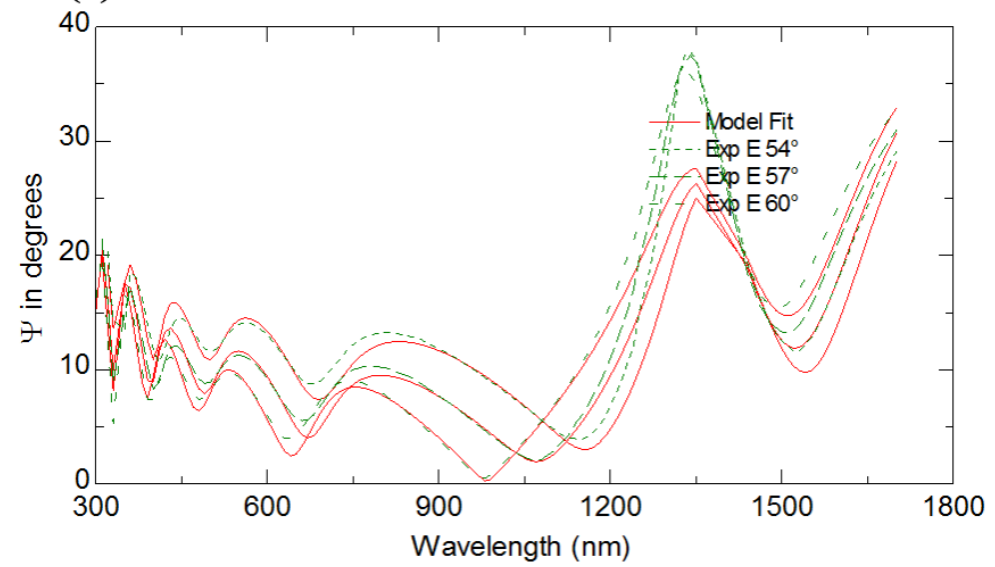

(b)

TEC 10, glass side

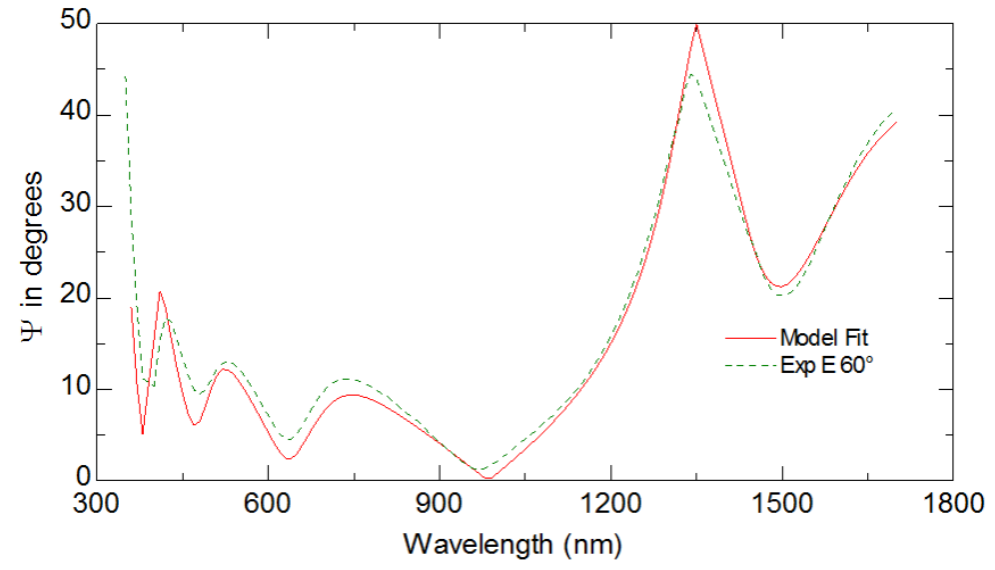

Figure 5. Model fits for ellipsometry on TEC 10 glass from a) the film side and b) the glass side.

Table 2. Parameters used to construct an optical model for TEC 10 glass.

\begin{tabular}{|c|c|c|}
\hline Layer & Parameter & Value \\
\hline \multirow{3}{*}{ Roughness } & Thickness & 38.9 \\
\hline \multirow{3}{*}{ SnO $_{\mathrm{x}}: \mathrm{F}$} & Thickness & $381.4 \mathrm{~nm}$ \\
\cline { 2 - 3 } & Drude - Amplitude & 1.8016 \\
\cline { 2 - 3 } & Drude - Broadening & .0835 \\
\cline { 2 - 3 } & Lorentz - Amplitude & 33.7 \\
\cline { 2 - 3 } & Lorentz - Broadening & $.477 \mathrm{eV}$ \\
\cline { 2 - 3 } & Lorentz - Energy & $5.56 \mathrm{eV}$ \\
\hline
\end{tabular}




\begin{tabular}{|c|c|c|}
\hline $\mathrm{SiO}_{2}$ & Thickness & $18.6 \mathrm{~nm}$ \\
\hline \multirow{3}{*}{$\mathrm{SnO}_{2}$} & Thickness & $35.845 \mathrm{~nm}$ \\
\cline { 2 - 3 } & Lorentz - Amplitude & 33.7 \\
\cline { 2 - 3 } & Lorentz - Broadening & $.477 \mathrm{eV}$ \\
\cline { 2 - 3 } & Lorentz - Energy & $5.75 \mathrm{eV}$ \\
\hline \multirow{2}{*}{ Glass } & Cauchy - An & 1.515 \\
\hline & Cauchy - Bn & .01 \\
\hline
\end{tabular}

Multiple samples were measured and produced nearly identical data. For further studies with films deposited on TEC 10, these layers were assumed to be constant and a single fixed model was used to represent the substrate.

\subsection{Cadmium sulfide layers deposited on TEC 10}

A number of reference samples were made consisting of only CdS layers on TEC 10 glass. These layers were used to verify that model thicknesses match measured thicknesses. The optical properties of the cadmium sulfide were taken from a reference value. The parameters that were allowed to vary were the CdS layer thickness and the thickness and void percent of an effective medium approximation (EMA) layer to account for surface roughness. Ellipsometry was performed at 60, 65, and 70 degrees from normal at wavelengths from 300nm to $1700 \mathrm{~nm}$.

For very thin layers, features in the data tend not to be as pronounced as for thicker layers and instead consist of slight oscillations. Often the best fits for thin layers have an EMA layer which is larger than the CdS layer thickness. This may be due to the fact that the TCO is rough and the TCO features under the CdS may be on the order of the CdS thickness itself. A graph comparing empirical data with a model fit is shown in Figure 6 and the numerical results for five reference $\mathrm{CdS}$ samples are shown in Table 3. For five 
reference samples of varying thicknesses, the CdS thickness (layer thickness plus EMA thickness) matches the profilometry measurement quite well as seen in Figure 6.

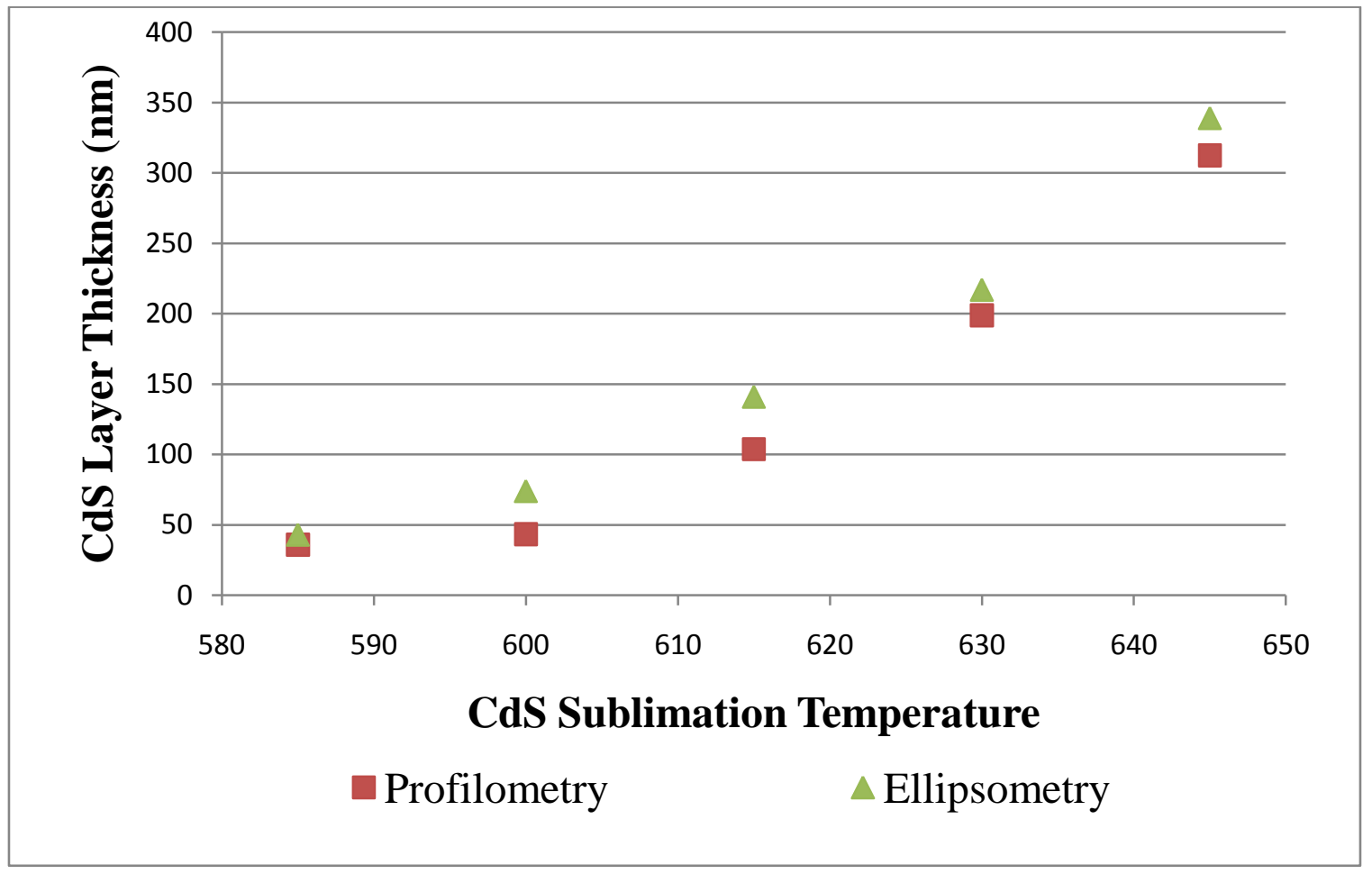

Figure 6. A comparison of CdS thickness measurements using stylus profilometry and ellipsometry.

Table 3. Profilometry thicknesses and Ellipsometry best-fit results for $5 \mathrm{CdS}$-on-TEC 10 samples.

\begin{tabular}{lrrrrrr} 
Sample & $\begin{array}{c}\text { CdS } \\
\text { Source } \\
\text { Temp }\end{array}$ & $\begin{array}{c}\text { Profilometry - } \\
\text { Avg. Thickness }\end{array}$ & $\begin{array}{c}\text { CdS } \\
\text { Thickness }\end{array}$ & $\begin{array}{c}\text { EMA } \\
\text { Thickness }\end{array}$ & $\begin{array}{c}\text { Void } \\
\text { \% }\end{array}$ & $\begin{array}{c}\text { Total } \\
\text { Thickness }\end{array}$ \\
\hline $70-3-1$ & 585 & $\mathbf{3 6}$ & 20 & 23 & 36 & $\mathbf{4 3}$ \\
\hline $73-7-1$ & 600 & $\mathbf{4 3}$ & 34 & 40 & 21 & $\mathbf{7 4}$ \\
\hline $73-3-1$ & 615 & $\mathbf{1 0 4}$ & 105 & 36 & 14 & $\mathbf{1 4 1}$ \\
\hline $70-6-1$ & 630 & $\mathbf{1 9 9}$ & 187 & 30 & 16 & $\mathbf{2 1 7}$ \\
\hline $73-6-1$ & 645 & $\mathbf{3 1 2}$ & 265 & 74 & 15 & $\mathbf{3 3 9}$
\end{tabular}


a) $70-6-5$

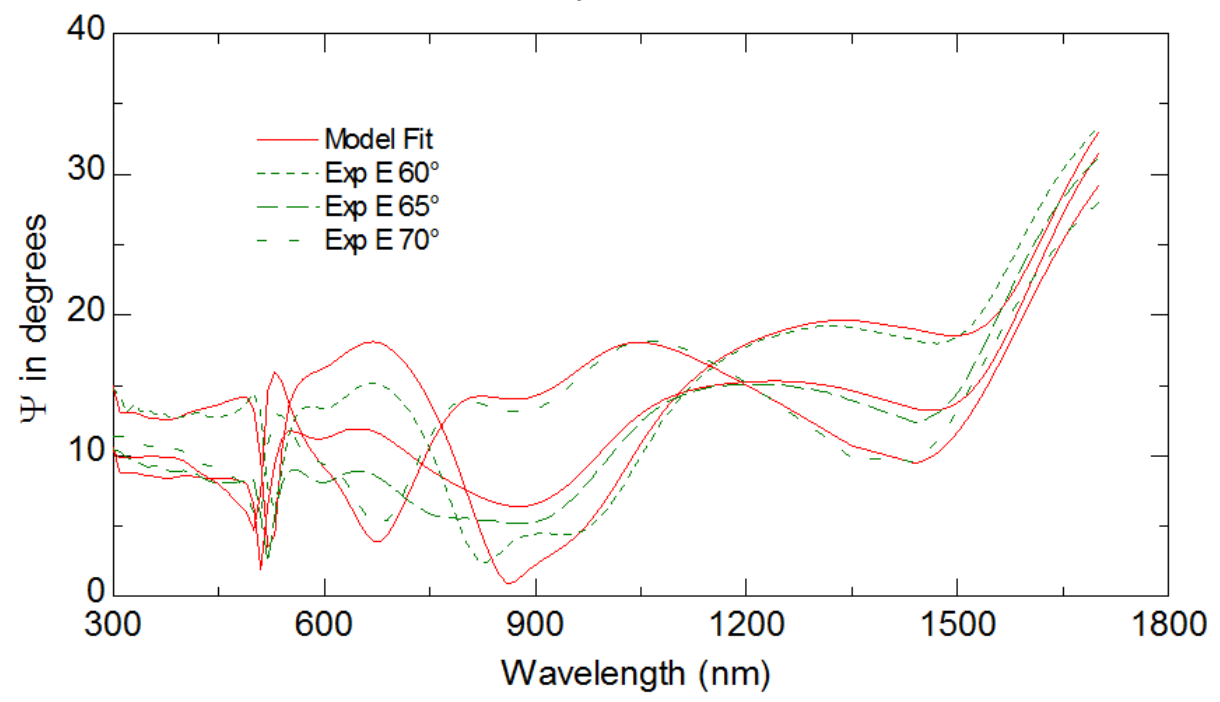

b) $70-3-5$

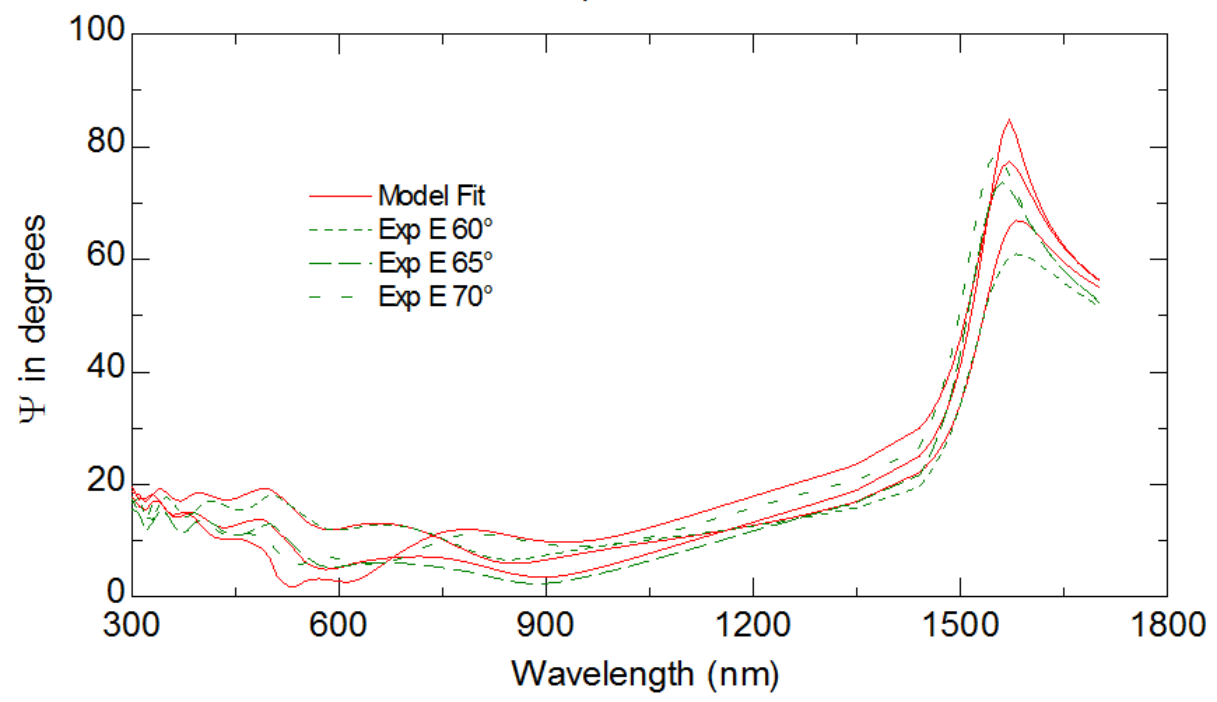

Figure 7. Typical ellipsometry best fits for a) a layer approximately $200 \mathrm{~nm}$ thick and b) approximately $50 \mathrm{~nm}$ thick.

\section{4 $\quad \mathrm{CdS} / \mathrm{CdTe}$ structures deposited on TEC 10}

In making some of the first devices on the ARDS, the CdTe morphology was very rough, with hemispherical features on the surface. In this case, the roughness makes performing film side ellipsometry impossible. To examine the changes in material 
properties with different treatments, films were polished in a slurry of 50-nm alumina in ethylene glycol. This produces a visually smooth film that reduces the influence of roughness on the empirical data.

Ellipsometry was performed above the bandgap to see if the empirical data changes from one sample to the other. In this optical regime, the CdTe film is opaque, so the ellipsometry data measures only properties at the surface. Because there is a wellcontrolled surface for all samples, and the effects of layer thicknesses and interfaces are eliminated, this should be a good measure of material property changes. Figure 8 shows a comparison of data for a CdTe film on TEC 10, a CdTe film on TEC 10 with $\mathrm{CdCl}_{2}$ treatment, a CdTe film with $\mathrm{CdCl}_{2}$ treatment and $\mathrm{Cu}$ doping, and a $\mathrm{CdTe}$ film on $\mathrm{CdS} / \mathrm{TEC} 10$ with $\mathrm{CdCl}_{2}$ treatment. This graph shows that there is almost no change between the treated and untreated films for $\psi$ at 65 degrees from normal; the film grown on CdS and post-treated may show some changes due to intermixing. It is also possible that these differences are simply due to slightly different polishing treatments.

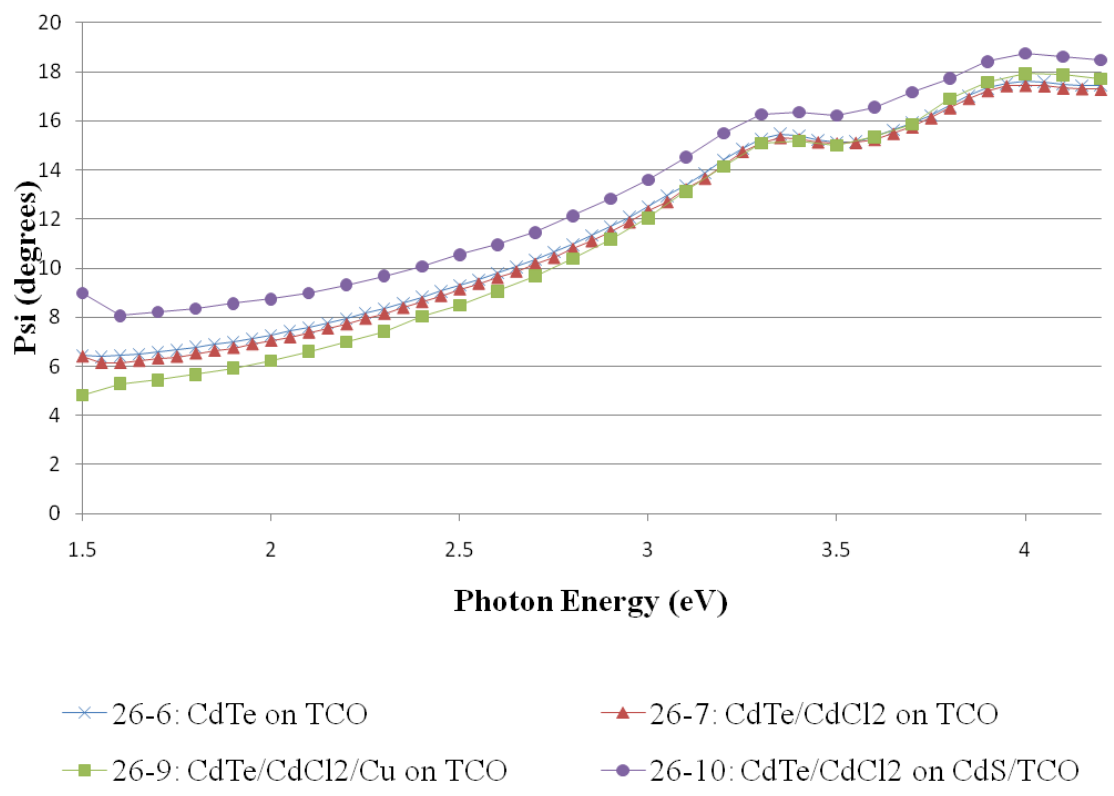

Figure 8. A comparison of above-bandgap ellipsometry data for four polished films. 
Since the films did not appear to show large differences in optical properties with various treatments, reference values were initially used to model the CdTe layer in devices. These values were taken from spectral reflectance measurements of single crystals [32]. Since films could not be measured for the hot set point samples, polished samples were measured, followed by samples made at the cold set point.

At the cold set point, a series of samples were made with varying CdS thickness. For each CdS thickness, a CdS and CdS/CdTe sample was made. These CdS films were measured with ellipsometry as well as profilometry. Then, fits were attempted for all the CdS/CdTe samples. Data was taken from 750 to $1700 \mathrm{~nm}$; at wavelength greater than about $850 \mathrm{~nm}$, all layers are transparent, and reflections between the layers create interference patterns in $\psi$ that indicate layer thicknesses. The surface, though much smoother than before, is still large and complex as it is still on the order of a wavelength of light. Many different surface layers were tried, including graded EMA layers. The best fits were found with an EMA layer of $20 \%$ void of about $70 \mathrm{~nm}$ thickness, and a top EMA layer of $40 \%$ void with a much smaller thickness of about $5 \mathrm{~nm}$. Originally there was also an $80 \mathrm{~nm}$ EMA layer between the TCO and CdS layers to account for interface roughness. The CdTe layer thickness has a large effect on the period of oscillations in the experimental data, and it is quite easy to get an accurate thickness for this layer. The CdS layer thickness, however, is more subtle and tends to affect the shape of the oscillations. With this model it is quite difficult to achieve a good fit for especially thin or thick CdS layers. Figure 9 compares a fit achieved for an approximately $200 \mathrm{~nm}$ CdS layer as well as a much thinner layer. 

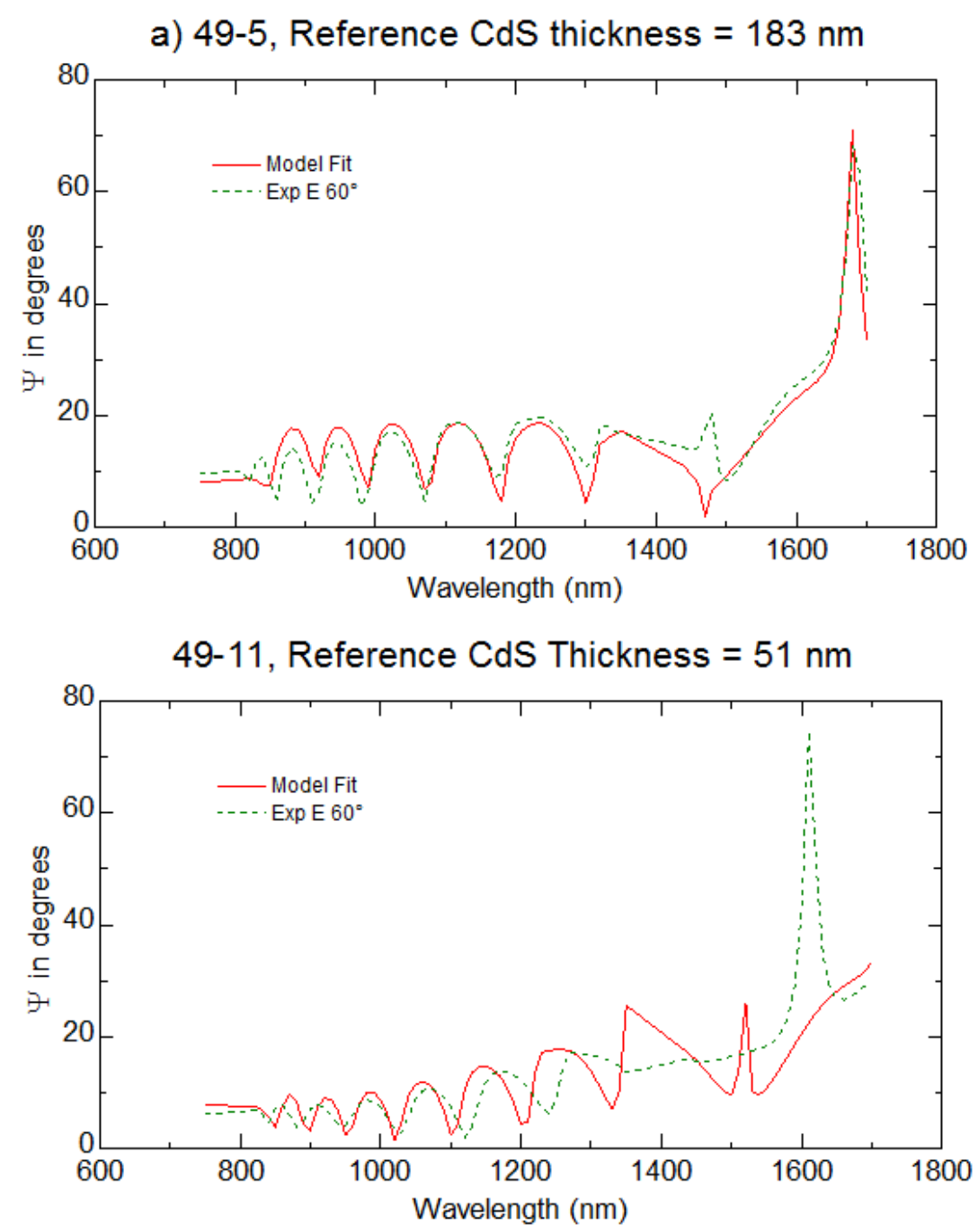

Figure 9. Using reference CdTe material properties, fits are much better for CdS films in the range of $200 \mathrm{~nm}$. a) a film with a reference CdS sample thickness of $183 \mathrm{~nm}$; the best fit thickness from the device was $167 \mathrm{~nm}$. b) A device with reference CdS thickness of 51 $\mathrm{nm}$. The best-fit thickness was $127 \mathrm{~nm}$ and the fit was poor.

At this point the pre-treated process condition was developed, and a study was created with a matrix of samples produced at $5 \mathrm{CdS}$ sublimation temperatures and $3 \mathrm{CdTe}$ sublimation temperatures. This matrix of thicknesses was produced over 3 ARDS runs along with 5 reference CdS samples. Ellipsometry was performed on all samples at 60, 65 and 70 degrees incidence from 750 to $1700 \mathrm{~nm}$ (primarily below the bandgap). 
For these pre-treated samples, it was found that a single EMA layer of approximately 70 $\mathrm{nm}$ at the surface, with a low void percentage that was allowed to vary, produced a satisfactory fit. Achieving an acceptable fit at very large and small CdS thickness values was still a problem. It was found that CdS thicknesses were skewed towards a value of about $150 \mathrm{~nm}$; that is, if the thickness was greater it was underestimated, and vice versa. Fits were especially poor near the band edge of CdTe, from 800 out to $1000 \mathrm{~nm}$ or so. To remedy this problem, the reference CdTe optical properties were replaced with an oscillator model. This oscillator model was fit to the reference value to have very similar refractive indices, $n$ and $k$. Then, a small amount of below-bandgap absorption was added and allowed to vary during the fit process. This absorption could be explained due to sulfur intermixing in the absorber layer, or could be accounting for scattering from the surface. It produced significantly better fits for all samples, and made the CdS thicknesses match reference values much more closely. The refractive indices are of the oscillator model are compared to the reference values in Figure 10. Since the pre-treated and cold, $\mathrm{CdCl}_{2}$-treated samples are quite similar and have higher sub-bandgap absorption, this could be attributed to sulfur intermixing, which should be greater for higher temperature processing and for samples with $\mathrm{CdCl}_{2}$ exposure. The smaller $\mathrm{n}$ for the cold, $\mathrm{CdCl}_{2}$ treated sample could be due to the voids seen in electron microscopy. 

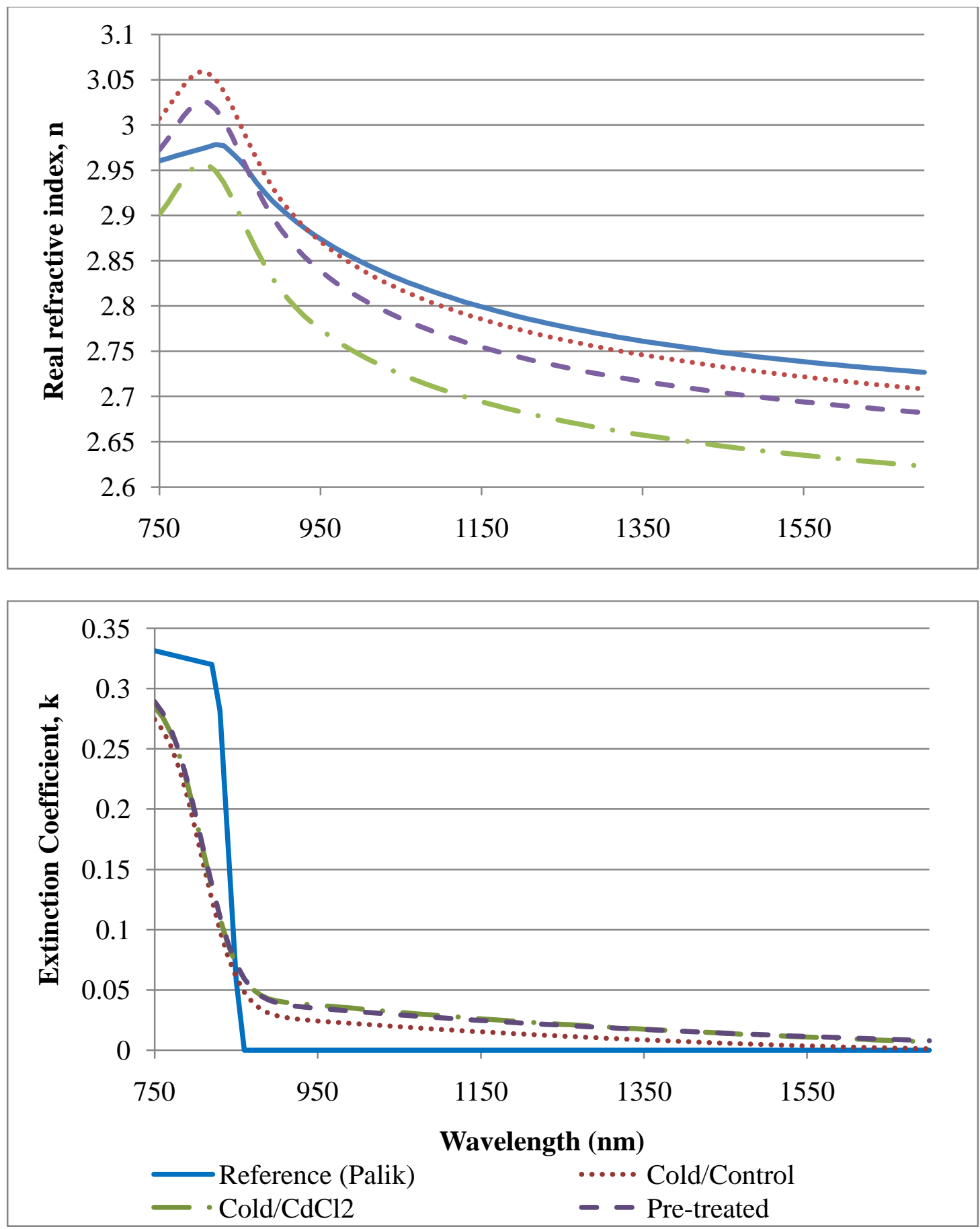

Figure 10. A comparison of the best-fit complex refractive indices of three samples to reference values. 
a) 69-6, Reference, MSE $=167.7$

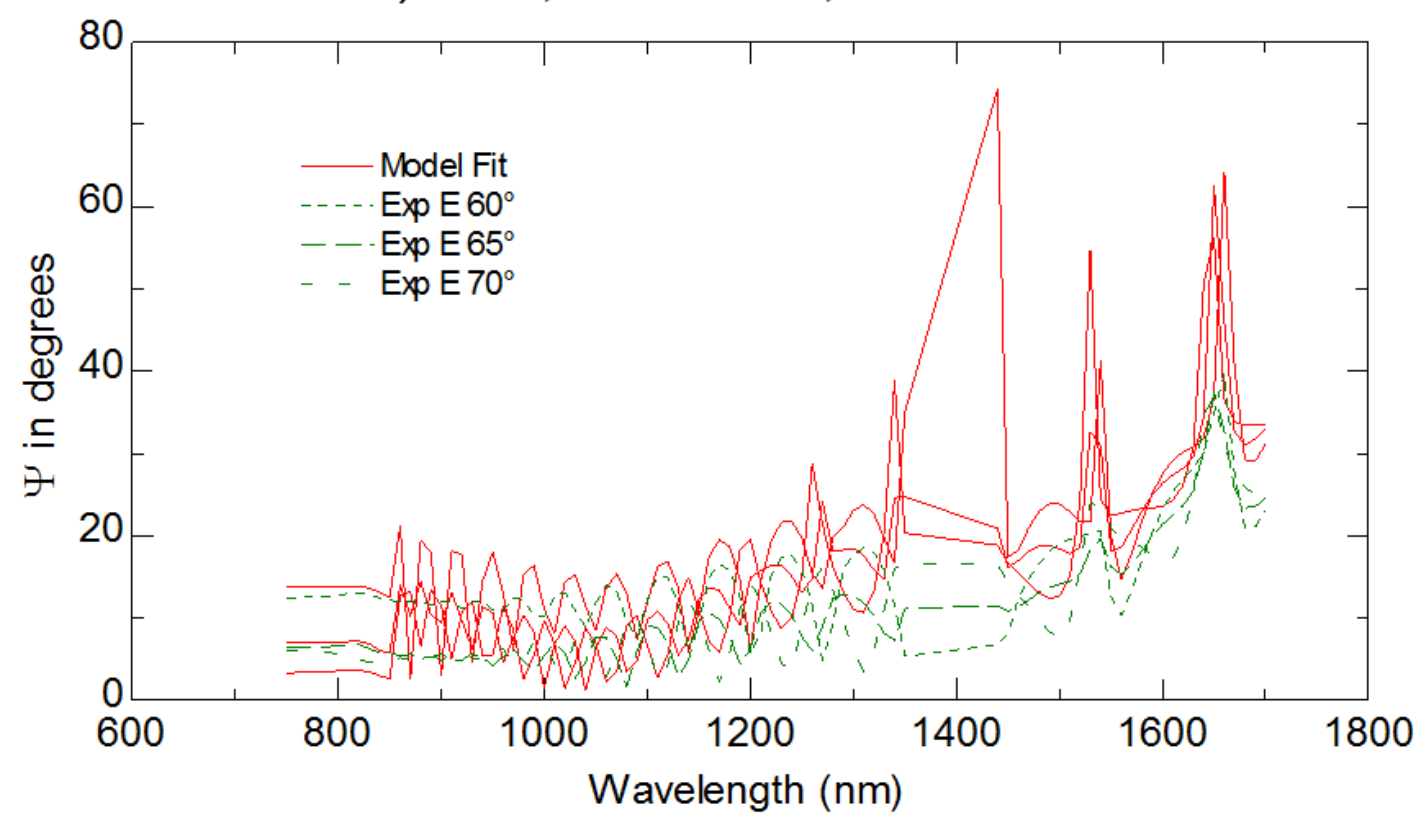

b) 69-6, Oscillator, MSE $=37.2$

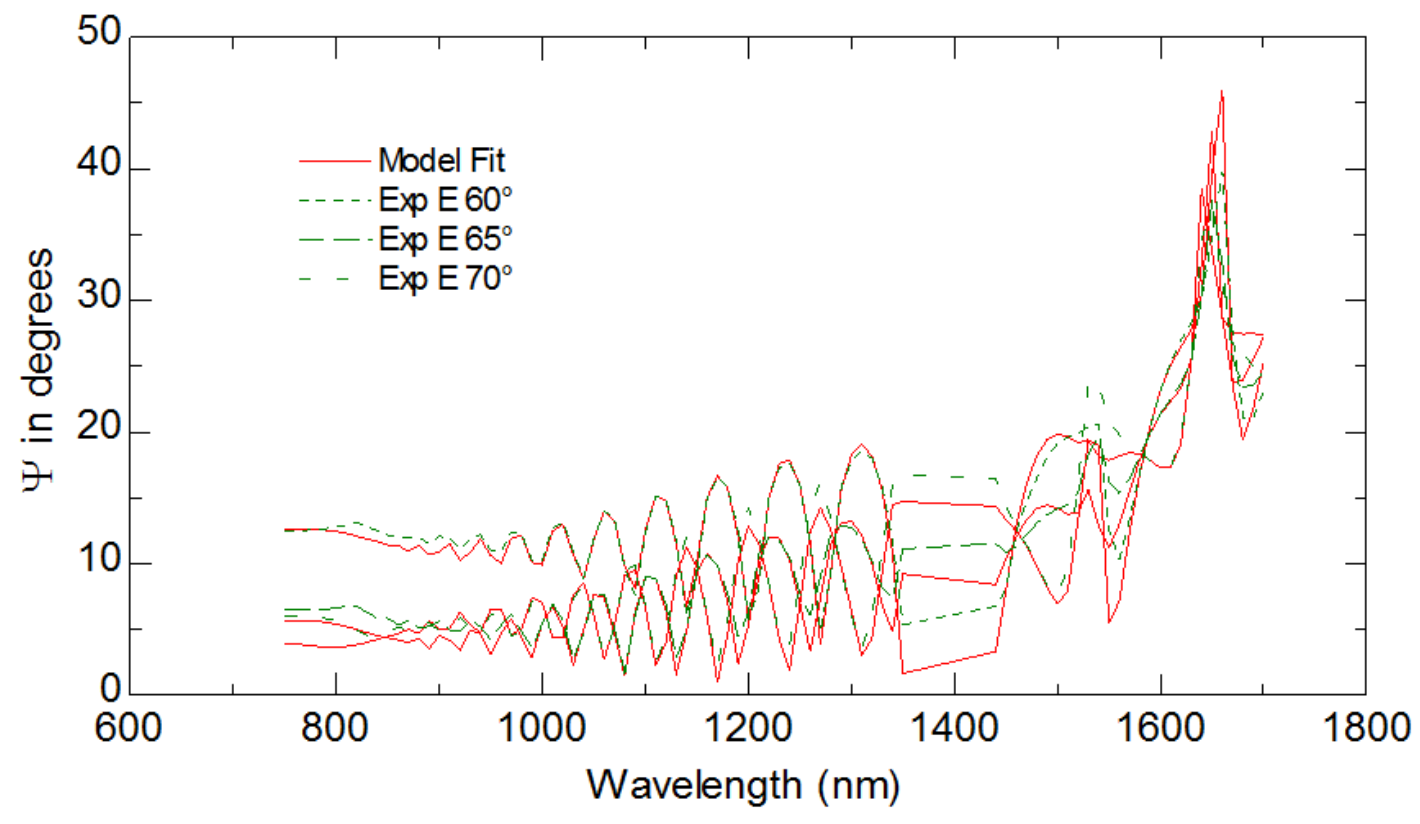

Figure 11. Mean squared error is greatly reduced for samples with thick or thin CdS by using an oscillator model for CdTe that allows for some sub-bandgap absorption. a) a best fit with reference optical properties, b) a best fit with an oscillator model.

With this model, 15 samples were fit and layer thicknesses were compared with a standard measurement. The CdS layer is compared to the profilometry measurement of 
the reference CdS-on-TCO sample. The CdTe layer is compared to the difference of the profilometry measurement for the device and the reference CdS thickness. The results of these comparisons are shown in Figure 12 and Figure 13. All thickness and fit data is summarized in Table 4.

CdTe thicknesses are accurate to the reference values within $4 \%$ except for one very thick sample which has approximately $10 \%$ error. The uncertainty of the reference measurement makes it difficult to understand the precision more definitively. For CdS measurements, very thin layers are underestimated, but otherwise the thicknesses match more closely.

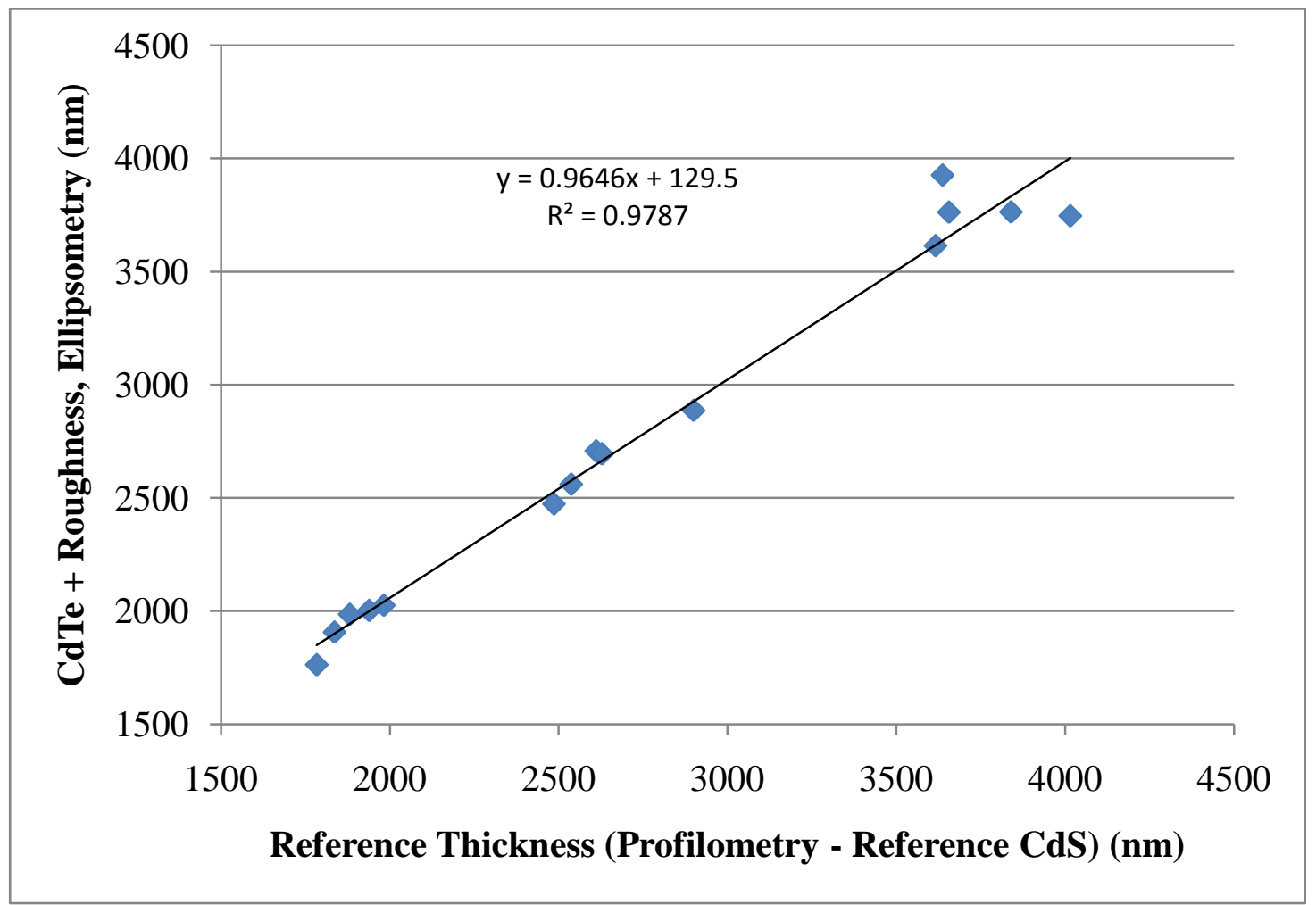

Figure 12. CdTe layer thicknesses measured by ellipsometry are compared to a reference measurement. 


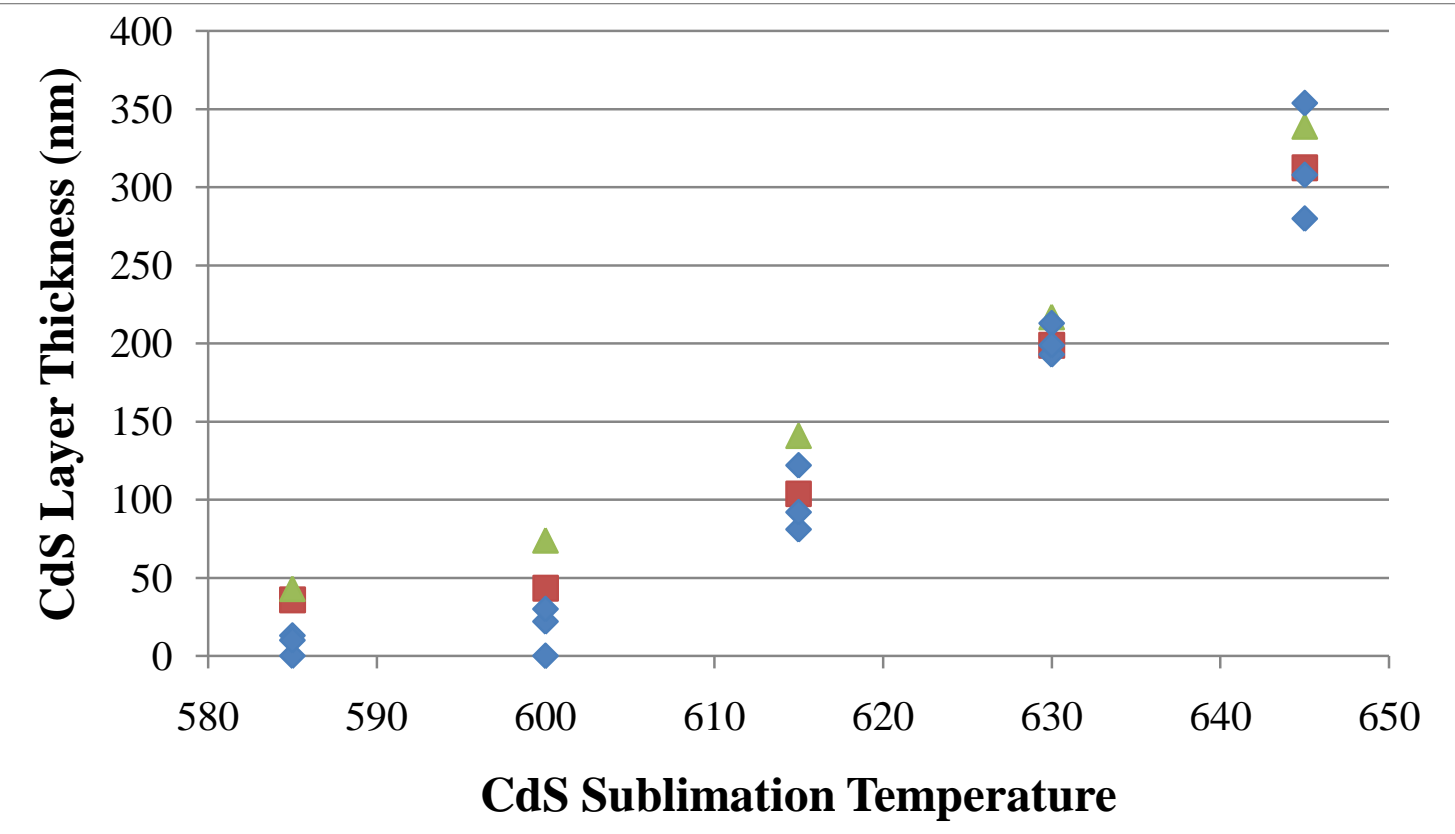

Reference, Profilometry $\quad \triangle$ Reference, SE $\quad \diamond$ Under CdTe, SE

Figure 13. A comparison of reference CdS samples measured by ellipsometry and profilometry to CdS layer thicknesses measured under CdTe films at three thickness set points.

Table 4. A summary of ellipsometry results for a thickness matrix of pre-treated samples.

\begin{tabular}{cccccccccc} 
& \multicolumn{1}{c}{} & \multicolumn{2}{c}{ Reference } & \multicolumn{3}{c}{ Ellipsometry } \\
Sample & $\begin{array}{c}\text { CdS } \\
\text { Temperature }\end{array}$ & $\begin{array}{c}\text { CdTe } \\
\text { Temperature }\end{array}$ & CdS & CdTe & CdS & CdTe & EMA & $\begin{array}{c}\text { CdTe + } \\
\text { Void \% }\end{array}$ \\
\hline $69-2-1$ & 600 & 565 & 53 & 2900 & 22 & 2816 & 71 & 16 & 2887 \\
\hline $69-3-1$ & 600 & 575 & 53 & 4016 & 0 & 3664 & 83 & 21 & 3747 \\
\hline $69-4-1$ & 645 & 565 & 316 & 2611 & 308 & 2635 & 73 & 16 & 2708 \\
\hline $69-5-1$ & 585 & 555 & 43 & 1982 & 13 & 1970 & 56 & 15 & 2026 \\
\hline $69-6-1$ & 645 & 575 & 316 & 3617 & 280 & 3537 & 78 & 17 & 3615 \\
\hline $69-7-1$ & 630 & 565 & 207 & 2628 & 193 & 2627 & 68 & 17 & 2695 \\
\hline $69-8-1$ & 615 & 565 & 123 & 2537 & 81 & 2495 & 66 & 18 & 2561 \\
\hline $70-2-1$ & 630 & 555 & 207 & 1783 & 213 & 1697 & 66 & 18 & 1763 \\
\hline $70-4-1$ & 585 & 575 & 43 & 3840 & 0 & 3697 & 67 & 17 & 3764 \\
\hline $70-5-2$ & 600 & 555 & 53 & 1938 & 30 & 1948 & 55 & 16 & 2003 \\
\hline $70-7-1$ & 585 & 565 & 43 & 2486 & 10 & 2420 & 54 & 16 & 2474 \\
\hline $70-8-1$ & 630 & 575 & 207 & 3656 & 199 & 3702 & 61 & 15 & 3763 \\
\hline $73-2-1$ & 645 & 555 & 316 & 1836 & 354 & 1844 & 63 & 21 & 1907 \\
\hline $73-4-1$ & 615 & 575 & 123 & 3637 & 92 & 3866 & 61 & 15 & 3927 \\
\hline $73-5-1$ & 615 & 555 & 123 & 1881 & 122 & 1938 & 48 & 17 & 1986
\end{tabular}


For pre-treated devices, a more complex graded EMA surface structure was examined to better match data above the CdTe bandgap by modeling the surface accurately. Above the bandgap, wavelengths are shorter (with increasing photon energy) and are more sensitive to surface features than at long wavelengths. Also, the film is opaque at this spectral range and only surface properties are being observed. A graded EMA was created with nodes at $30 \%, 60 \%$ and $100 \%$ of the film (100\% is the top surface) where the void percentage was allowed to vary. Reference CdTe refractive indices were used, and a thick layer of CdTe was placed below the surface layers to model no light reaching other interfaces. The overall thickness of this graded EMA was also allowed to vary. The results usually indicate a large thickness of low void content—-for sample 69-7 after a fit was performed, the layer was $165 \mathrm{~nm}$ thick, with the void percentages of $7.3 \%, 14.8 \%$, and 29.0\% respectively. This matches AFM and SWLI profiles which show large grains with deep crevices between them. Figure 14 shows the fit of this model to above-bandgap ellipsometry data.

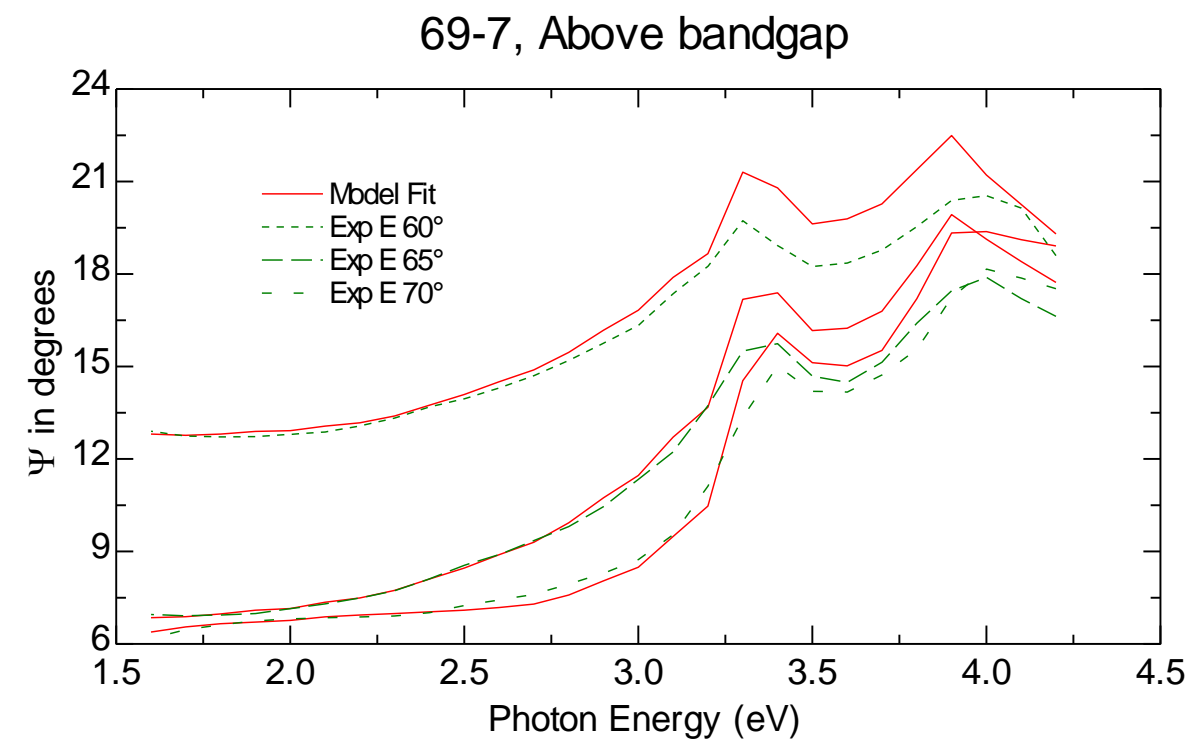

Figure 14. A graded EMA layer matches above bandgap data well. 


\subsection{Effects of the $\mathrm{CdCl}_{2}$ post-treatment on $\mathrm{CdS} / \mathrm{CdTe}$ structures}

For samples at the cold set point conditions, the small, columnar grains are recrystallized in the $\mathrm{CdCl}_{2}$ treatment. This can be seen in the $\mathrm{SEM}$. $\mathrm{CdCl}_{2}$-treated samples and control $\mathrm{CdS} / \mathrm{CdTe}$ samples were created at this condition for five $\mathrm{CdS}$ thicknesses. For the thicker layers, more of a difference between the treated and control samples could be seen. This is possibly due to sulfur intermixing, but could also be due to voids created during recrystallization which can be seen by SEM in Figure 15.
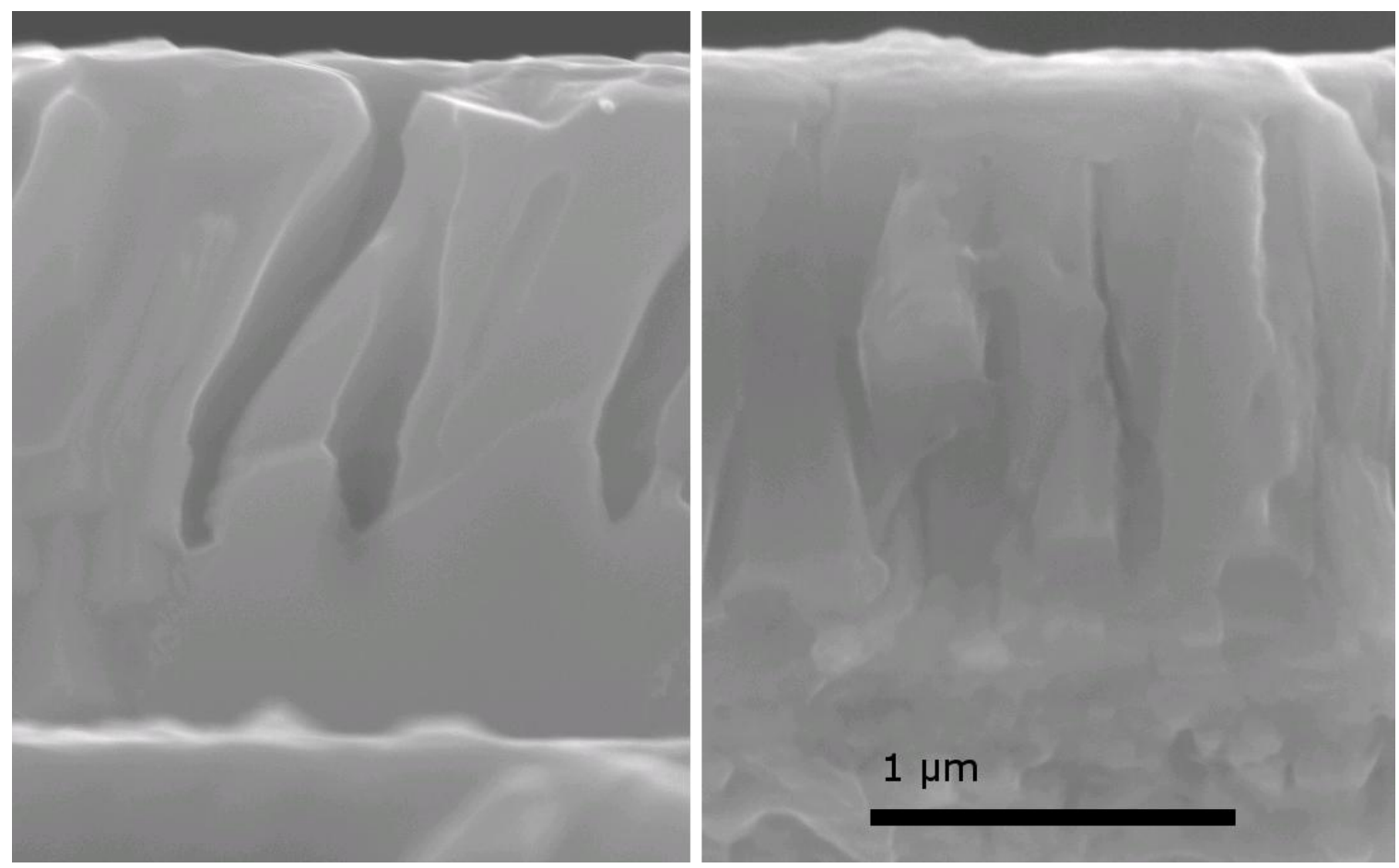

Figure 15. On the left is a $\mathrm{CdCl}_{2}$-treated sample, and on the right is a control sample. Voids are created in recrystallization by the $\mathrm{CdCl}_{2}$ treatment for samples at the cold process condition.

The resulting ellipsometry data shows qualitatively different data, although the period of oscillations are very similar between samples. By using an oscillator model with subbandgap absorption as in the previous section, both samples produced a good fit, as 
shown in Figure 16. This may be due to intermixing of sulfur during the $\mathrm{CdCl}_{2}$ treatment or scattering of light by the voids in the treated sample.

a) 49-3, Control

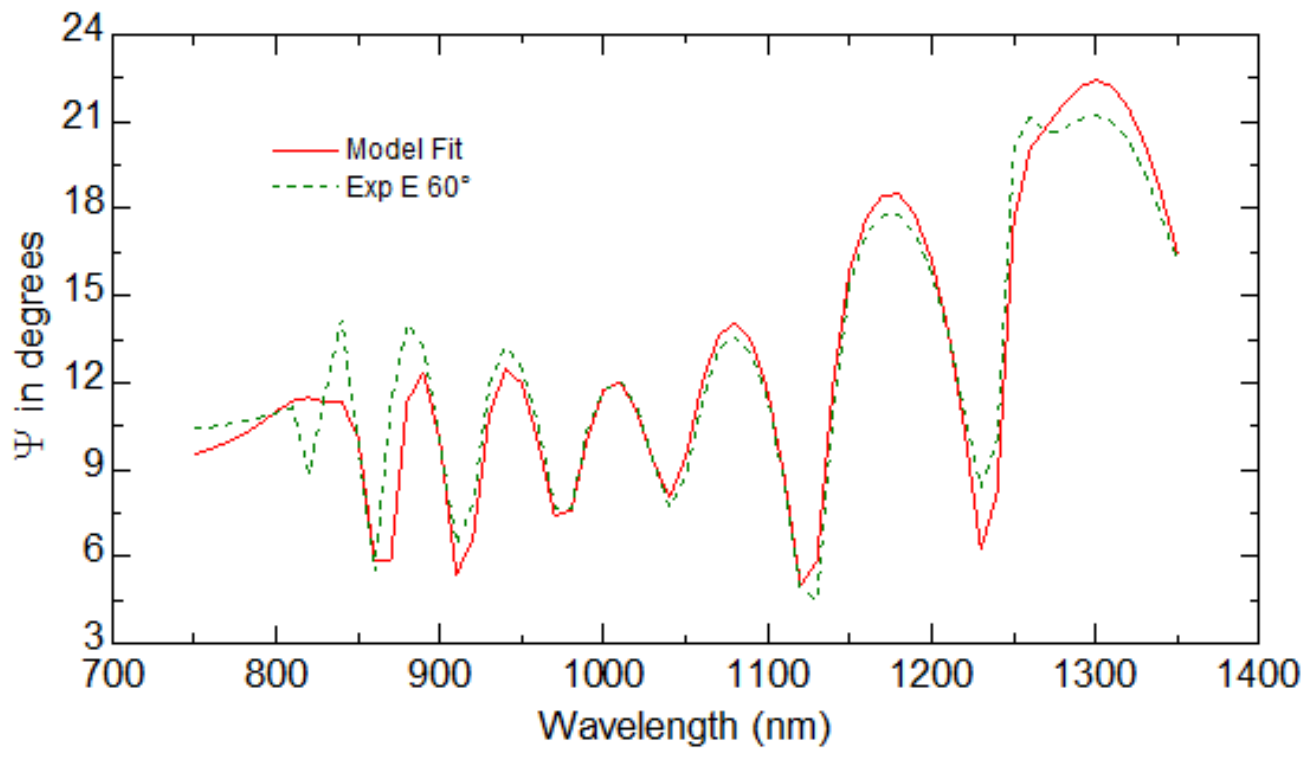

b) $49-15, \mathrm{CdCl} 2$ Treated

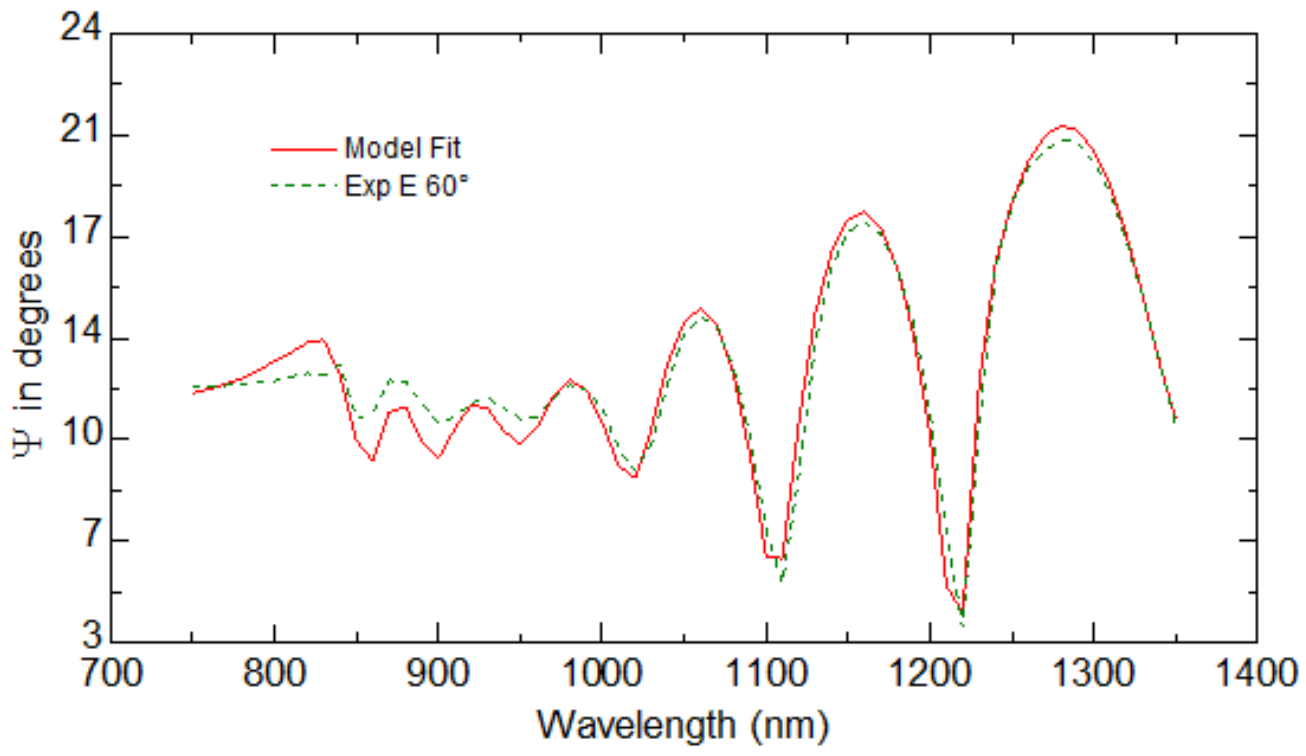

Figure 16. Samples produced at the same set point. a) CdS and CdTe layers only b) $\mathrm{CdCl} 2$-treated layers. Data shown at one angle for clarity. 
A study was also performed on samples made at the pre-treated set point. Samples were made at the same conditions for film deposition, but were placed in the $\mathrm{CdCl}_{2}$ station for varying amounts of time (different multiples of the $110 \mathrm{~s}$ cycle). One sample was also given a $\mathrm{Cu}$ treatment to see if any clear differences appeared. As can be seen from comparing the raw data, there is a slight vertical shift which may be due to slight differences in the surface roughness of the samples, as this tends to disappear for longer wavelengths. Otherwise, the data look very similar and no differences appear that are clearly more than small random differences in thickness or surface properties. This likely indicates that there is no recrystallization and minimal sulfur diffusion from the $\mathrm{CdCl}_{2}$ treatment for devices made at this set point.

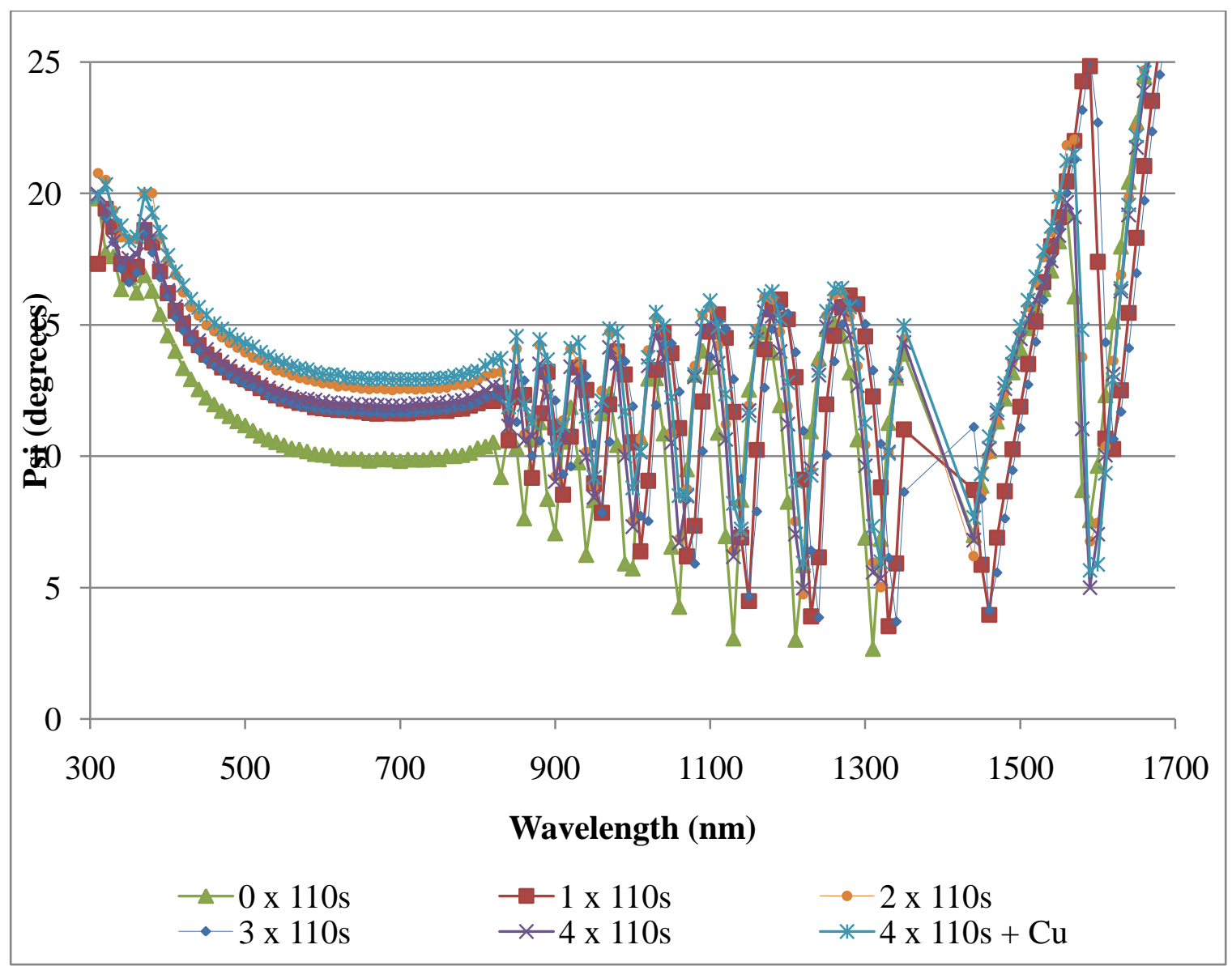

Figure 17. Pre-treated samples exposed to varying $\mathrm{CdCl} 2$ treatments. 


\subsection{Through-the-glass ellipsometry}

There are numerous potential advantages to performing ellipsometry through the glass as opposed to the film side. The measurement could be performed on a completed module, and if the film were too rough to measure from the film side, it could still be possible to determine something about the CdS layer underneath. A more subtle reason this could be an advantage is that information can be collected on the sub-layers in the region of light where CdTe is opaque. When traveling through the glass, the light refracts to an angle much closer to normal (for 60 incidence the real angle through the glass is about 35 degrees). Also, the primary reflection from the front surface of the glass is not coherent with the reflections from the film surfaces at the back, and must be blocked from the detector [28].

Some experiments were done using this technique. First, the standard alignment techniques were performed with the ellipsometer to capture the reflection from the front surface. Then the sample was moved a precise, calculated distance so the beam from the rear surface of the glass would be centered in the detector. Finally the aperture to the detector was made as small as possible to reduce noise from the front surface beam. This approach is explained by Chen et al. and is shown in Figure 18.

The approach was tried on numerous samples. The TEC 10 glass was fit so that the model worked well from the glass and film sides, as discussed previously. An ellipsometry model was constructed in which the glass was considered the ambient medium, and the angle was altered manually to account for the refraction in to the glass. For a full device, often it is not possible to obtain data near the $\mathrm{CdS}$ band edge; this is not well understood. Otherwise, rough fits have been obtained which match film side and 
reference thicknesses to first order. A major difference can be seen between rough and smooth samples. For a very rough sample, the light is scattered at the back of the CdTe layer, and no oscillations from this layer can be seen. For a smooth layer, many oscillations are evident in the transparent region. To model the rough sample, the CdTe was considered a substrate (infinitely thick) so no reflections from its back surface were modeled. Figure 19 shows the results for a rough sample and a smooth sample with their model fits.

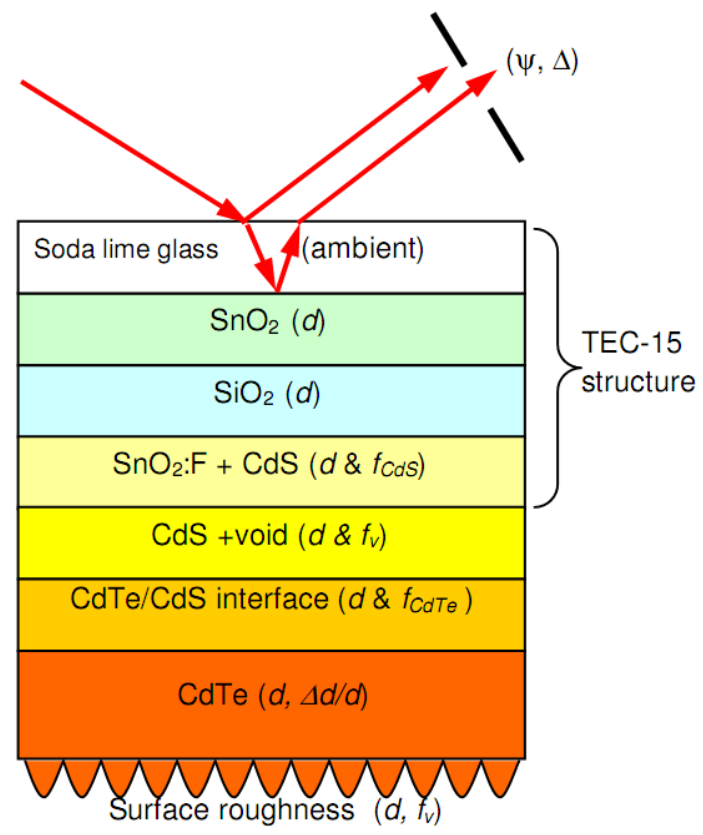

Figure 18. Through-the-glass ellipsometry [28]. 

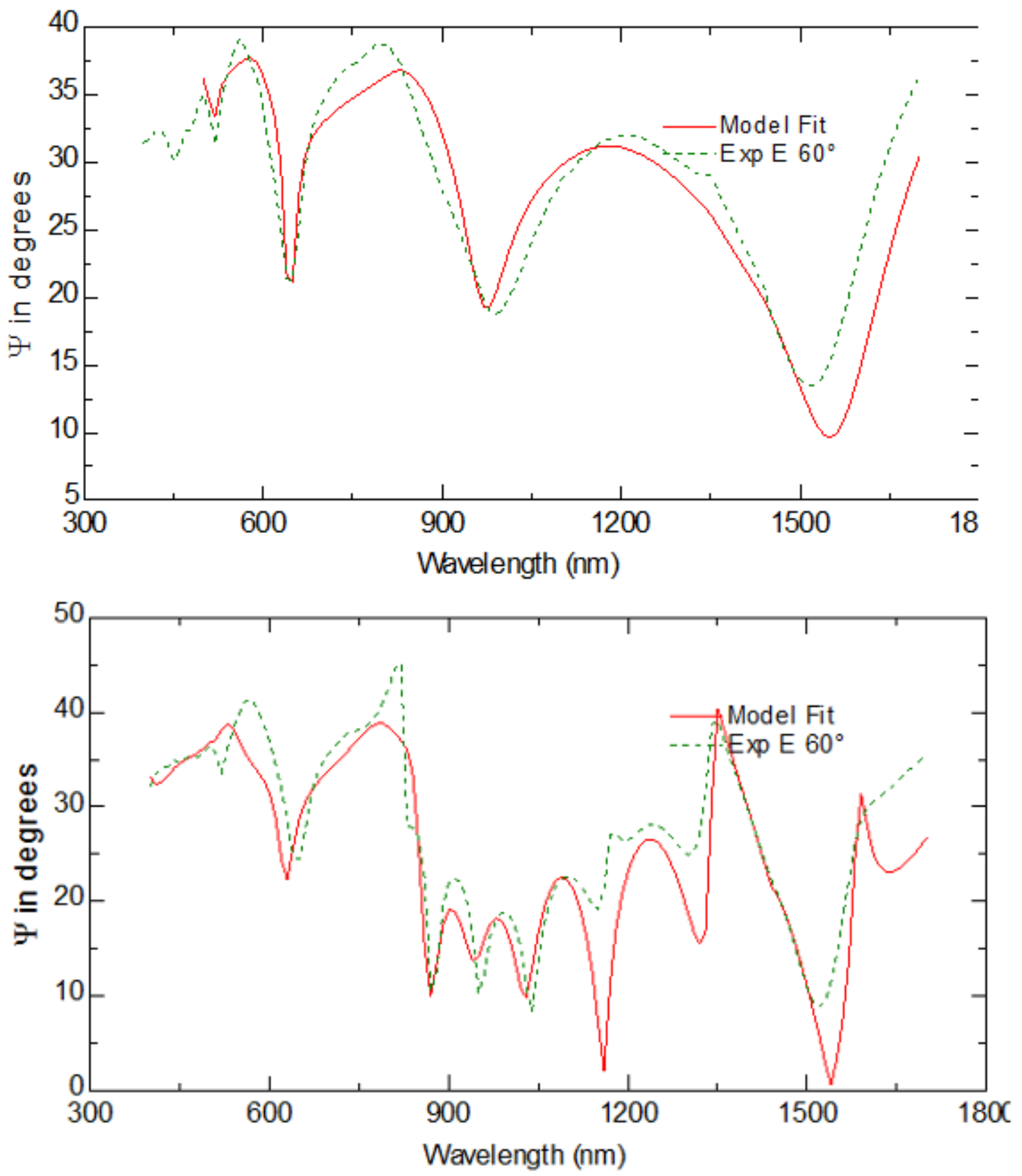

Figure 19. Through-the-glass ellipsometry fits for a rough (top) and smoother sample with the same CdS thickness. 


\section{CHAPTER 5: ANALYSIS OF SCANNING WHITE LIGHT INTERFEROMETRY}

\section{RESULTS}

\subsection{Motivation}

As previously discussed, ellipsometry results are highly sensitive to surface morphology, and failure to properly model these effects can cause inaccurate measurements of device structure and thickness. Furthermore, processing conditions have a large effect on the morphology of CdTe films. A fast, optical method for measuring surface roughness could not only serve as an on-line manufacturing tool for checking consistent process conditions, but could help corroborate ellipsometry results to ensure accurate structural measurement. Because of SWLI's excellent depth resolution, it was compared to a standard nano-scale surface roughness measurement tool—atomic force microscopy (AFM) - to determine if measurements of roughness were well-correlated.

In addition to surface morphology, SWLI has potential to measure scribes in the module production process. To see the potential accuracy of such measurements, steps etched from many samples were measured via stylus profilometry and SWLI and the thickness values were compared.

\subsection{Roughness correlation with AFM}

The first samples measured were a very rough sample made at the hot process and a smoother sample made at the pre-treated process condition. The very rough sample had a large amount of spurious data points which were clearly noise. In Figure 20a, many single points can be seen which rise far above all adjacent points, which makes it difficult to see the actual morphology of the sample. In part b, a spike removal as well as a low- 
pass Gaussian filter with $500 \mathrm{~nm}$ wavelength was added to remove these spikes. The grain morphology of the samples is clearly visible.

(a)

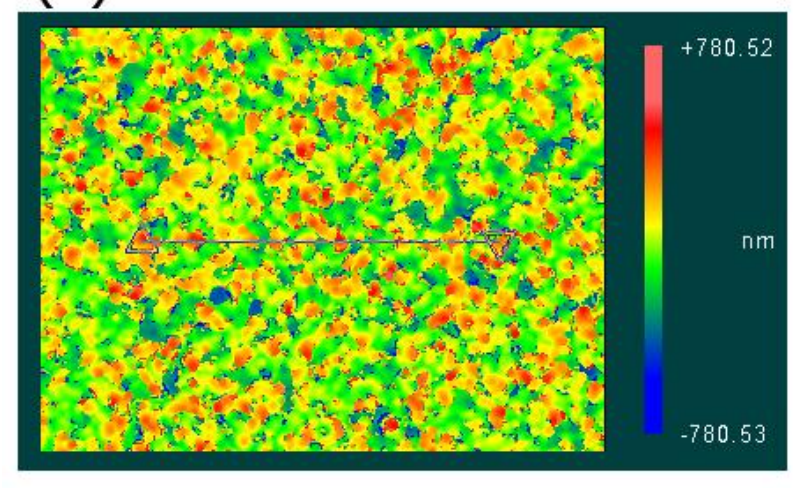

(b)

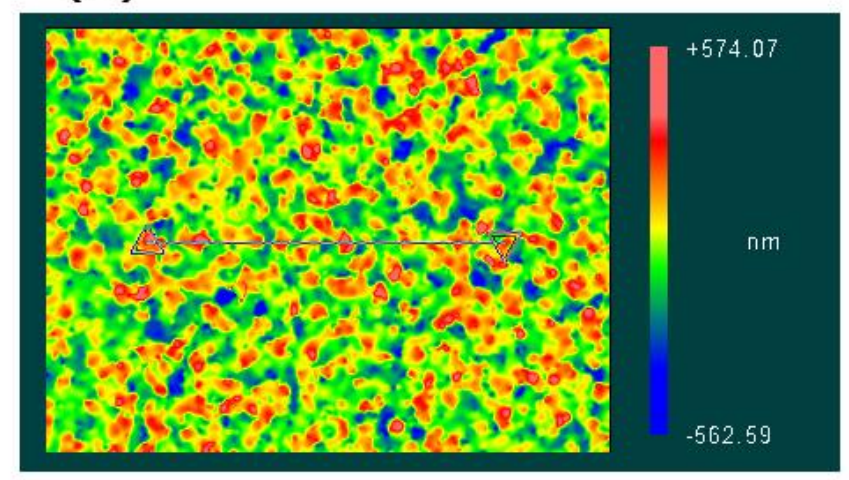

Figure 20. a) Very rough samples can produce noisy data-spikes are seen as red dots. b) The same data with more clearly visible grain structure after a spike removal and lowpass filter.

The thickness matrix of 15 samples made at the pre-treated process condition were measured by SWLI with $200 X$ objective magnification somewhere near the middle of the sample in three locations, spaced $1 \mathrm{~mm}$ apart. The three $10-\mu \mathrm{m}$ square images were measured for surface RMS roughness. This average was compared to the surface RMS value of a nearby spot measured with a AFM on a 5- $\mu$ m square with 256 samples/line. The resulting $\mathrm{R}^{2}$ value of .80 seen in Figure 21 indicates a strong correlation between the two measurement methods. A major source of variance could be due to the small sample area of the AFM data. The data are well correlated, but clearly show a systematic difference in the actual roughness value produced. SWLI roughness values could be higher due to the ability of the optical technique to measure further into crevices than with a scanning probe, which could "ride" over them. Additionally, there appears to be an outlier for the roughest sample; with this point removed the $\mathrm{R}^{2}$ value is 0.86 . Additionally to a simple roughness correlation, samples were examined qualitatively at the same depth 
scale to see if the morphology seen with SWLI was similar to the AFM images. For sample 69-5 this comparison is shown in Figure 22.

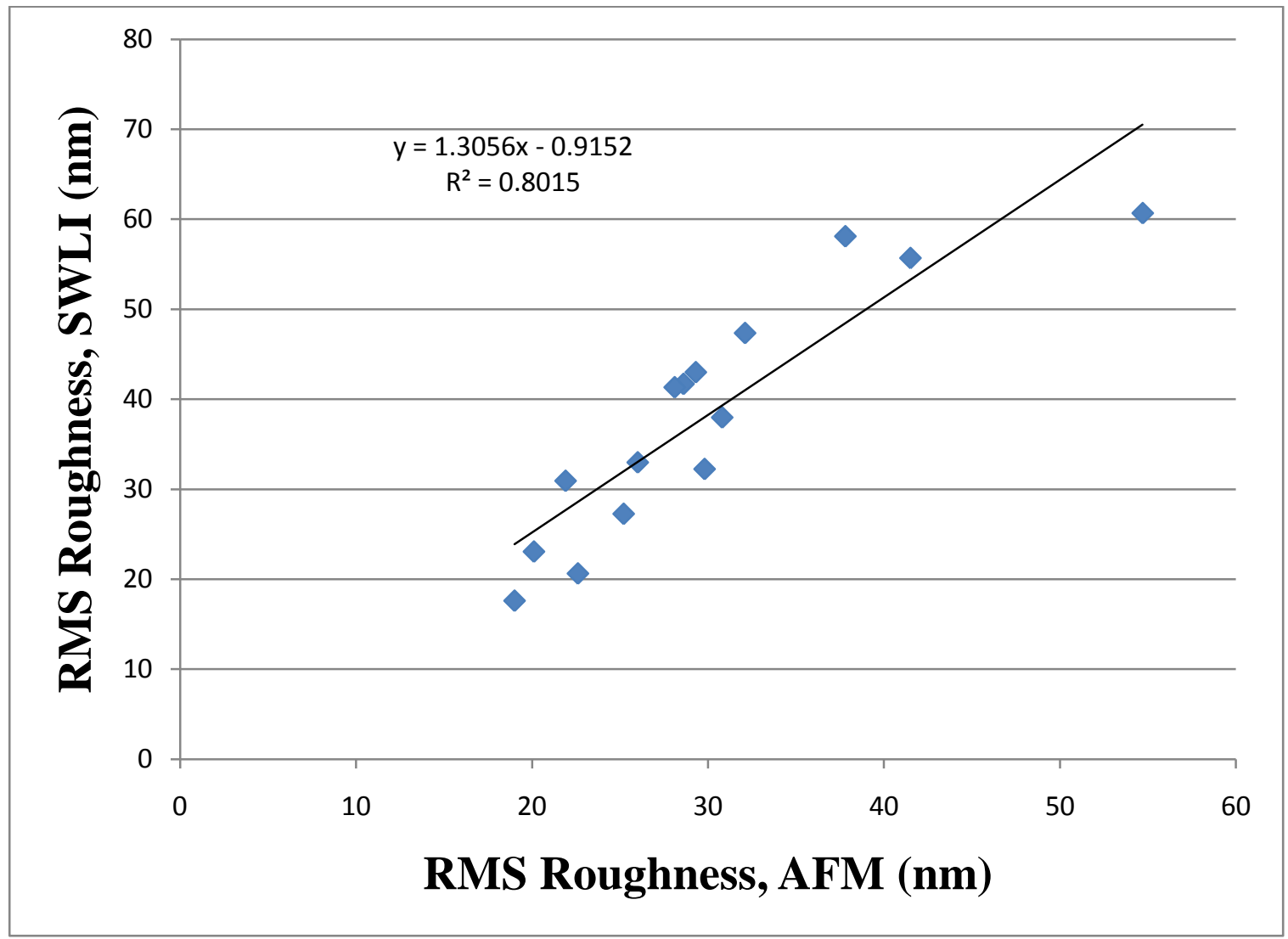

Figure 21. SWLI $\mathrm{S}_{\mathrm{RMS}}$ values correlate fairly well with those of AFM.

(a)

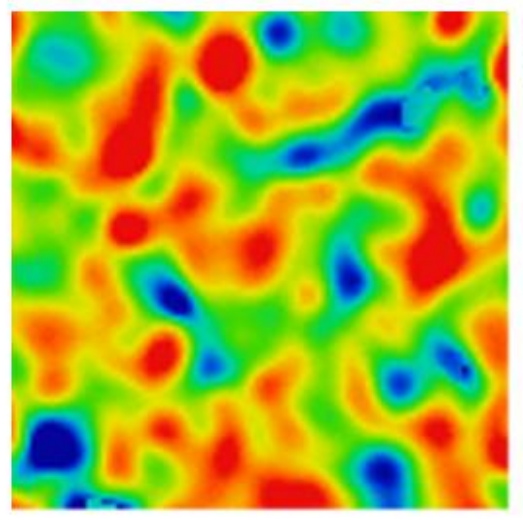

(b)

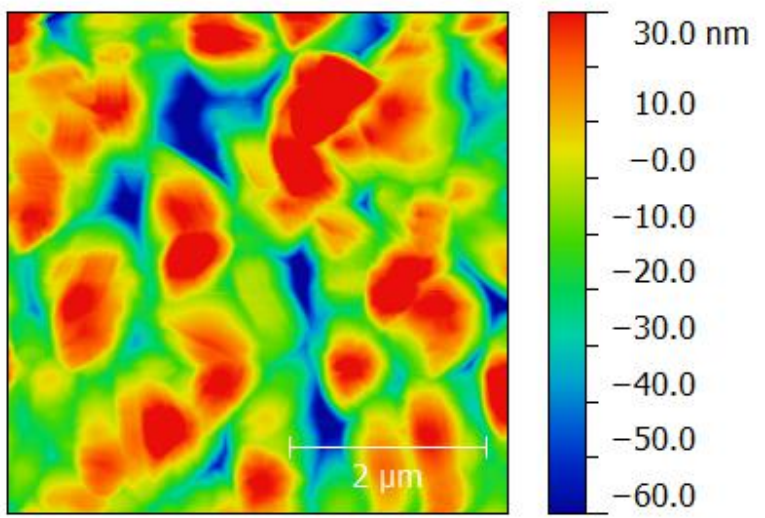

Figure 22. SWLI and AFM produce qualitatively similar surface morphology images.

5.3 Step height measurement 
CdTe solar modules are deposited monolithically on a sheet of glass, and individual cells are made by a series of laser scribes that connect long strips of film in series. These scribes can be very deep, on the order of or much larger than a wavelength of light, and have steep walls. Interferometry is based on phase difference, which can be confounded if the slope between points is greater than one quarter wavelength of light. The ability to precisely measure these depth scales is a necessary condition for SWLI to be useful as a scribe metrology tool. For this study, steps were etched in the films by masking an area with electroplating tape and etching the exposed film away with a bromine-methanol solution. The 15 samples from the thickness matrix study of pre-treated samples were measured with this technique and compared with profilometry. SWLI step heights were determined by subtracting the average height of a plane on the exposed TCO from the height of an area on the film surface. Profilometry heights are measured from a previously discussed approach. The results, shown in Figure 23 show excellent agreement and a near-perfect coefficient of determination. 


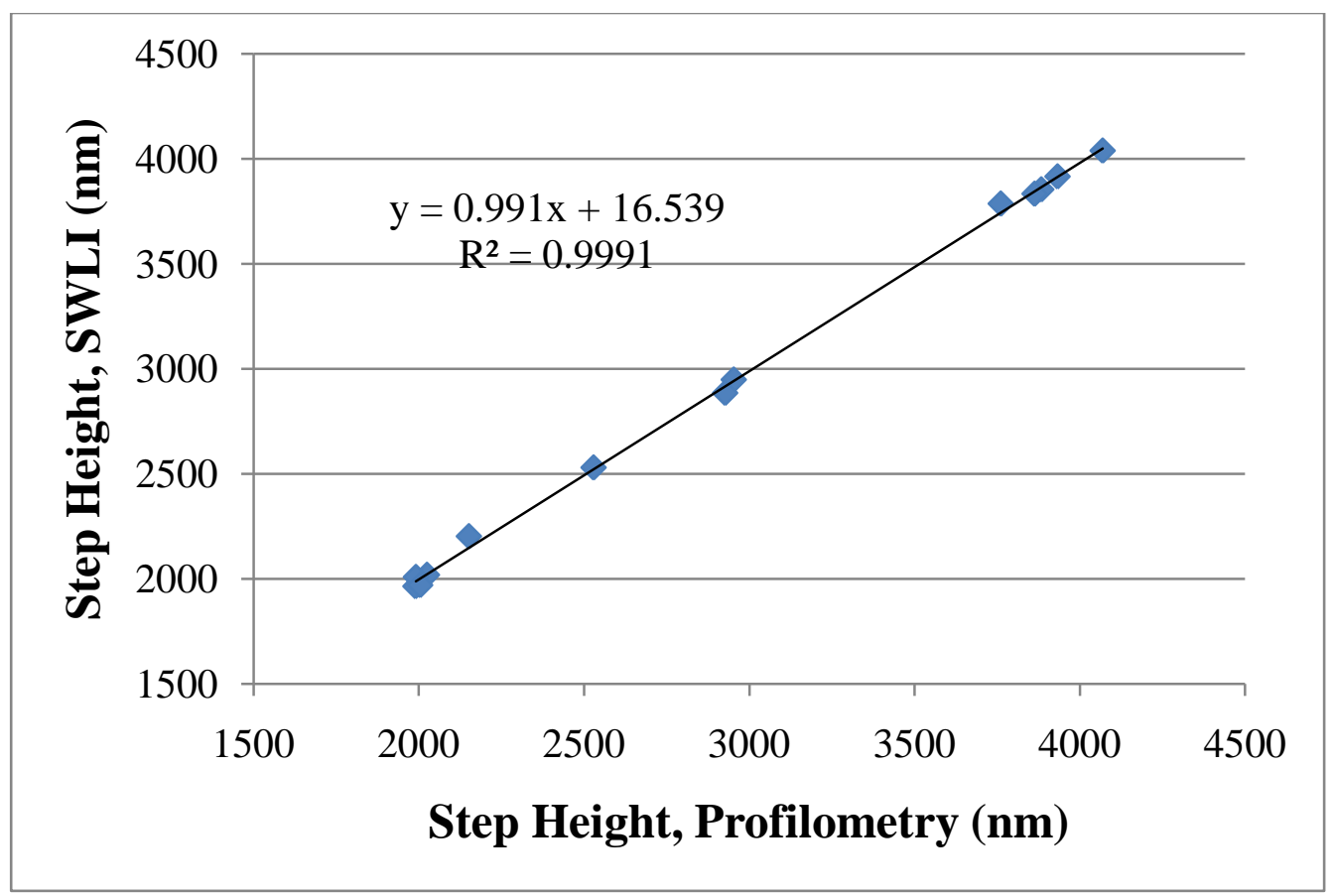

Figure 23. Step height thickness measurements comparing profilometry to SWLI. 


\section{CHAPTER 6: Conclusions}

\subsection{Perspective and Summary of Results}

The motivation for this work was to show the feasibility of using optical characterization techniques for the structural characteristics. Roughness has been shown to be the most important obstacle to accurate and consistent results with ellipsometry. A number of process spaces were examined for the production of films with more favorable morphologies. Ellipsometry has been shown to measure the thickness of the CdTe absorber quite accurately, and to measure the CdS thickness reasonably well under the absorber layer. Emphasis was placed on the use of a consistent model to measure multiple samples. Slight modifications to the reference material properties improved the ellipsometry model fits over a wide range of $\mathrm{CdS}$ thicknesses.

Scanning white light interferometry was also examined as a replacement for contactbased measurement techniques such as stylus profilometry or atomic force microscopy. It has been shown to accurately measure large step heights such as those that could be produced by laser scribing. It has also demonstrated the ability to resolve grain structure, and its surface roughness measurements correlate well with AFM.

The work presented here is preliminary in nature. Since much of the work was devoted to bringing the ARDS into operation and finding suitable process spaces in which to make devices with a better surface and grain structure, many aspects of this research may not be relevant to films produced at high-efficiency manufacturing process conditions. However, the feasibility of using these techniques for the proposed measurements has been shown and further refinements should enable more accurate and robust results. 


\subsection{Future Work}

An important aspect of this work was not simply showing an ellipsometry model with a good fit to experimental data, but a simple model with relatively few parameters which can be fit to many devices with varying layer thicknesses. This model should be refined, and if possible compared to more direct and precise reference measurements. Layer thicknesses should be made to match more closely over a wide range of CdS layer thicknesses. The first step for this would be to develop a better understanding of how to model thin CdS layers with no CdTe present. More work should be done to confirm the reason that small amounts of sub-bandgap absorption improve the model fit. For throughthe-glass studies, work could be done to more exactly model the glass and rear surfaces. Ellipsometry performed with focusing optics could be used to model very rough films in which large amounts of scattering occur. This could lead to a more robust model of wavelength-scale roughness that could less vulnerable to variations in morphology.

For interferometry studies, more work could be done adjusting filter parameters and examining the reasons that the RMS roughness values are well correlated to AFM but tend to be larger. Additionally, this roughness information should be correlated to ellipsometry to see if it can predict best-fit EMA layer properties. More actual scribes (P1, P2, and P3) should be measured with this technique and correlated to optimum module properties such as series resistance. On the whole, these measurement techniques show promising results but much work remains before they will be ready for in-line process control environments. 


\section{REFERENCES}

[1] U.S. Energy Information Administration, 2011, Annual Energy Outlook 2011.

[2] Smalley R. E., 2005, "Future global energy prosperity: the terawatt challenge," Mrs Bulletin, 30(06), pp. 412-417.

[3] U.S. Energy Information Administration, 2010, International Energy Outlook, U.S. Dept of Energy, Washington, DC.

[4] Solomon, S., D. Qin, M. Manning, R.B. Alley, T. Berntsen, N.L. Bindoff, Z. Chen, A. Chidthaisong, J.M. Gregory, G.C. Hegerl, M. Heimann, B. Hewitson, B.J. Hoskins, F. Joos, J. Jouzel, V. Kattsov, U. Lohmann, T. Matsuno, M. Molina, N. Nicholls, J. Overpeck, G. Raga, V. Ramaswamy, J. Ren, M. Rusticucci, R. Somerville, T.F. Stocker, P. Whetton, R.A. Wood, and D. Wratt, 2007, "Technical Summary," Climate Change 2007: The Physical Science Basis. Contribution of Working Group I to the Fourth Assessment Report of the Intergovernmental Panel on Climate Change., Solomon, S., D. Qin, M. Manning, Z. Chen, M. Marquis, K.B. Averyt, M. Tignor, and H.L. Miller, eds., Cambridge University Press, Cambridge, U.K.

[5] Fackler M., 2011, “Japan Scraps Plan for New Nuclear Plants," New York Times.

[6] U.S. Energy Information Administration, 2009, Annual Energy Review, U.S. Dept. of Energy, Washington, DC.

[7] Koonin S. E., 2006, “Getting serious about biofuels,” Science, 311(5760), p. 435.

[8] International Energy Agency, 2010, Technology Roadmap: Solar Photovoltaic Energy.

[9] Zweibel K., 2005, "Photovoltaics Past the Tipping Point."

[10] Wolden C. A., Kurtin J., Baxter J. B., Repins I., Shaheen S. E., Torvik J. T., Rockett A. A., Fthenakis V. M., and Aydil E. S., 2011, "Photovoltaic Manufacturing: Present status, future prospects, and research needs," J. Vac. Sci. Technol. A, 29(3).

[11] Hook J. R., and Hall H. E., 2006, Solid State Physics, John Wiley \& Sons, Chichester, U.K.

[12] Gray, J.L., 2003, “The Physics of the Solar Cell," Handbook of Photovoltaic Science and Engineering, John Wiley \& Sons.

[13] Shockley W., and Queisser H. J., 1961, "Detailed Balance Limit of Efficiency of p n Junction Solar Cells," Journal of Applied Physics, 32, p. 510. 
[14] Sites J., and Pan J., 2007, "Strategies to increase CdTe solar-cell voltage," Thin Solid Films, 515(15), pp. 6099-6102.

[15] Chu T., and Chu S., 1995, "Thin-film II-VI Photovoltaics," Solid-State Electronics, 38(3), pp. 533-549.

[16] McCandless B. E., Moulton L. V., and Birkmire R. W., 1998, "Recrystallization and sulfur diffusion in $\mathrm{CdCl} 2$-treated $\mathrm{CdTe} / \mathrm{CdS}$ thin films," Progress in

Photovoltaics: Research and Applications, 5(4), pp. 249-260.

[17] Durose K., Asher S. E., Jaegermann W., Levi D., McCandless B. E., Metzger W., Moutinho H., Paulson P. D., Perkins C. L., and Sites J. R., 2004, "Physical characterization of thin-film solar cells," Progress in Photovoltaics: Research and Applications, 12(2-3), pp. 177-217.

[18] Fujiwara H., 2007, Spectroscopic Ellipsometry: Principles and Applications, John Wiley \& Sons, West Sussex, England.

[19] Zapien J. A., Jie Chen, Jian Li, Inks J., Podraza N. J., Chi Chen, Drayton J., Vasko A., Gupta A., Wang S. L., Collins R. W., and Compaan A. D., 2005, "Real time spectroscopic ellipsometry of thin film CdTe deposition by magnetron sputtering for photovoltaic applications," Photovoltaic Specialists Conference, 2005.

Conference Record of the Thirty-first IEEE, pp. 461-464.

[20] Guide to using WVASE32, J.A. Woollam Co.

[21] Wyant J. C., 2002, “White light interferometry,” Proc. SPIE, pp. 98-107.

[22] Nouruzi-Khorasani A., Lunn M. A., Jones I. P., and Dobson D. J., 1990, "Surface damage of CdTe by mechanical polishing investigated by cross-sectional TEM," Journal of Crystal Growth, 102(4), pp. 1069-1073.

[23] Aspnes D. E., and Arwin H., 1984, "Nondestructive analysis of Hg1-xCdxTe (x= $0.00,0.20,0.29$, and 1.00 ) by spectroscopic ellipsometry. I. Chemical oxidation and etching," Journal of Vacuum Science \& Technology A: Vacuum, Surfaces, and Films, 2(3), pp. 1309-1315.

[24] Arwin H., and Aspnes D. E., 1984, "Nondestructive analysis of Hg1- xCdxTe (x= $0.00,0.20,0.29$, and 1.00) by spectroscopic ellipsometry. II: Substrate, oxide, and interface properties," Journal of vacuum science and technology. A. Vacuum, surfaces, and films, 2(3), pp. 1316-1323.

[25] Wei K., Pollak F. H., Freeouf J. L., Shvydka D., and Compaan A. D., 1999, “Optical properties of CdTe1-xSx $(0 \leq x \leq 1)$ : Experiment and modeling," Journal of Applied Physics. 
[26] Li J., Podraza N. J., and Collins R. W., 2008, "Real time spectroscopic ellipsometry of sputtered CdTe, CdS, and CdTe(1-x)Sx thin films for photovoltaic applications," physica status solidi (c), 205(4), pp. 901-904.

[27] Li J., Chen J., and Collins R. W., 2008, "Analysis of the dielectric functions of CdS and CdTe for grain size, stress, and temperature: Potentialities for on-line monitoring," Photovoltaic Specialists Conference, 2008. PVSC '08. 33rd IEEE, pp. 1-6.

[28] Jie Chen, Jian Li, Thornberry C., Sestak M. N., Collins R. W., Walker J. D., Marsillac S., Aquino A. R., and Rockett A., 2009, "Through-the-glass spectroscopic ellipsometry of CdTe solar cells," Photovoltaic Specialists Conference (PVSC), 2009 34th IEEE, pp. 001748-001753.

[29] Zhiquan Huang, Jie Chen, Sestak M. N., Attygalle D., Dahal L. R., Mapes M. R., Strickler D. A., Kormanyos K. R., Salupo C., and Collins R. W., 2010, "Optical mapping of large area thin film solar cells," Photovoltaic Specialists Conference (PVSC), 2010 35th IEEE, pp. 001678-001683.

[30] Von Rottkay K., and Rubin M., 1996, "Optical Indices Of Pyrolytic Tin-Oxide Glass," Materials Research Society Symposium Proceedings, pp. 449-454.

[31] Kohli S., Manivannan V., Hilfiker J. N., McCurdy P. R., Enzenroth R. A., Barth K. L., Smith W. P., Luebs R., Kephart J., and Sampath W. S., 2010, "Effect of chemical treatment on the optical properties of a cdte photovoltaic device investigated by spectroscopic ellipsometry," Photovoltaic Specialists Conference (PVSC), 2010 35th IEEE, pp. 001951-001954.

[32] Palik E. D., 1998, “Cadmium Telluride (CdTe)," Handbook of Optical Constants of Solids, Academic Press, London, pp. 409-427. 